\title{
Self-assembled nanoparticles based on amphiphilic chitosan derivative and arginine for oral curcumin delivery
}

This article was published in the following Dove Press journal:

International Journal of Nanomedicine

6 September 2016

Number of times this article has been viewed

\section{Mazhar Ali Raja \\ Shah Zeenat \\ Muhammad Arif \\ Chenguang Liu}

College of Marine Life Science, Ocean University of China, Qingdao, Shandong, People's Republic of China
Correspondence: Chenguang Liu College of Marine Life Science, Ocean University of China, No 5 Yushan Road, Qingdao 266003, Shandong, People's Republic of China

Tel +8653282032102

Fax +8653282032586

Email liucg@ouc.edu.cn
Abstract: Curcumin (Cur) is a striking anticancer agent, but its low aqueous solubility, poor absorption, hasty metabolism, and elimination limit its oral bioavailability and consequently hinder its development as a drug. To redress these limitations, amphiphilic chitosan (CS) conjugate with improved mucoadhesion and solubility over a wider $\mathrm{pH}$ range was developed by modification with hydrophobic acrylonitrile (AN) and hydrophilic arginine (Arg); the synthesized conjugate (AN-CS-Arg), which was well characterized by Fourier transform infrared and ${ }^{1} \mathrm{H}$ nuclear magnetic resonance spectroscopy. Results of critical aggregation concentration revealed that the AN-CS-Arg conjugate had low critical aggregation concentration and was prone to form self-assembled nanoparticles (NPs) in aqueous medium. Cur-encapsulated AN-CS-Arg NPs (AN-CS-Arg/Cur NPs) were developed by a simple sonication method and characterized for the physicochemical parameters such as zeta potential, particle size, and drug encapsulation. The results showed that zeta potential of the prepared NPs was $40.1 \pm 2.81 \mathrm{mV}$ and the average size was $\sim 218 \mathrm{~nm}$. A considerable improvement in the aqueous solubility of Cur was observed after encapsulation into AN-CS-Arg/Cur NPs. With the increase in Cur concentration, loading efficiency increased but encapsulation efficiency decreased. The in vitro release profile exhibited sustained release pattern from the AN-CS-Arg/Cur NPs in typical biological buffers. The ex vivo mucoadhesion study revealed that AN-CS-Arg/Cur NPs had greater mucoadhesion than the control CS NPs. Compared with free Cur solution, AN-CS-Arg/Cur NPs showed stronger dose-dependent cytotoxicity against HT-29 cells. In addition, it was observed that cell uptake of AN-CS-Arg/Cur NPs was much higher compared with free Cur. Furthermore, the in vivo pharmacokinetic results in rats demonstrated that the AN-CS-Arg/Cur NPs could remarkably improve the oral bioavailability of Cur. Therefore, the developed AN-CS-Arg/Cur NPs might be a promising nano-candidate for oral delivery of Cur.

Keywords: curcumin, self-assembled, nanoparticles, cytotoxicity, cell uptake studies, oral bioavailability

\section{Introduction}

Cancer is the multifaceted and most distressing disease which represents one of the leading causes of death worldwide. Statistics from the World Health Organization reports 8.2 million cancer deaths in the year 2012 and the number of patients is increasing every year. ${ }^{1}$ So far, the most common approach for the treatment of cancer is the removal of tumor followed by extensive chemotherapy, radiotherapy, and immunotherapy. Chemotherapy remains the mainstay of treatment, and most of the chemotherapeutic drugs are administered parenterally, causing severe adverse effects due to impulse concentrations in blood stream leading to poor patients' compliance and 
ultimately to failure of therapy. ${ }^{2-6}$ Oral delivery of anticancer agents could be a feasible alternative to parenteral administration, since it can avoid fluctuation of drug concentration, minimize drug-related adverse effects, and thus improve the overall efficacy of drugs; moreover, patients are more receptive to it. ${ }^{7-9}$ However, the oral delivery of anticancer agents is often associated with low bioavailability due to the first-pass effect and physical absorption barriers in gastrointestinal tract (GIT). ${ }^{10,11}$ Therefore, it has increasingly become an urgent medical need to develop a safer, targeted, and better oral anticancer drug delivery system.

Curcumin (Cur), a naturally active component extracted from rhizomes of turmeric (Curcuma longa), has a wellestablished history of utilization in the People's Republic of China and India not only as additive in foods but also as a natural remedy in medicines. Moreover, it possesses diverse biological and pharmacological activities, including antioxidant, anti-inflammatory, anticancer, and antidepressant properties. ${ }^{12-14}$ It is worth notable that no severe adverse drug reaction associated with Cur has been reported so far in conducted clinical trials and research signifying Cur as safest anticancer drug. ${ }^{15}$ Currently, the US National Cancer Institute has considered Cur as a third-generation chemotherapeutic drug. ${ }^{16}$ Unfortunately, the clinical progression of Cur has been hindered due to several challenges. For example, the low aqueous solubility of Cur leads to the limited bioavailability and poor in vivo pharmacokinetics, which subsequently restricts the therapeutic effect. ${ }^{17}$ Another drawback is the insufficient systemic absorption through the digestive tract after oral administration. The improvement in Cur's oral bioavailability has become a medical and pharmaceutical need as major portion of the drug never reaches the plasma to exert its pharmacological effects. Plasma concentrations as well as therapeutic and toxic effects are directly influenced by the extent of bioavailability, resulting after oral Cur administration. Hence, it is therapeutically important to improve the oral bioavailability of Cur. ${ }^{18}$ Therefore; efforts are being made for the exploration of novel formulations to circumvent these pitfalls and to utilize the full potential of Cur as anticancer agent. ${ }^{19,20}$

Till date, various Cur delivery systems have been investigated, including polymeric micelles, ${ }^{21}$ solid lipid nanoparticle (NP), ${ }^{22}$ polymeric NPs, ${ }^{23}$ biodegradable microspheres, ${ }^{24}$ phospholipids, ${ }^{25}$ cyclodextrin, ${ }^{26}$ hydrogel, ${ }^{27}$ and liposome. ${ }^{28,29}$ Among these delivery systems, polymeric NPs, due to their ultra-small size, posses the added advantage that they can pass through the smallest capillary vessels and avoid hasty clearance by phagocytes, and thus their duration is greatly extended in blood stream. ${ }^{30}$ Furthermore, these NPs can be utilized for targeted delivery of drugs to improve bioavailability, to sustain drug in target tissues, and to improve the stability of therapeutic agents. ${ }^{31,32}$ Properties of the NPs are largely dependent on the polymer employed..$^{33}$

Among these polymeric NPs, chitosan (CS)-based nanocarriers have received much attention as a drug delivery system. ${ }^{34} \mathrm{CS}$ has been well reported to be the most widespread biopolymer having nontoxic, biocompatible, and biodegradable characteristics. ${ }^{35}$ In addition, the most common approach for oral Cur delivery is the encapsulation of drug using mucoadhesive polymers such as CS by which the drug is physically protected from enzymatic degradation and intestinal juices. Besides, mucoadhesive in nature CS can enhance the penetration of drugs across mucosal barrier by its interactions with epithelial tight junctions, thereby facilitating transport of drugs across mucosal membrane and improving pharmacological effects. ${ }^{36,37}$ Although the CS possess impressive array of biomedical benefits, the effectiveness of CS application has been limited due to its drawback of poor aqueous solubility at physiological $\mathrm{pH}$, which can be overcome by chemical modification. ${ }^{38,39}$ After structural manipulation and functionalization of $\mathrm{CS}$, drug molecule can be encapsulated and the advantages of encapsulating Cur within the CS polymer allow for a greater control of the active drug pharmacokinetic behavior. ${ }^{18}$

Amino acids, the building blocks of proteins, are considered as chiral molecules having low molecular weight and different properties based on their side chains. The inclusion of amino acid moieties to the backbone of CS has been shown to improve the physicochemical properties of $\mathrm{CS}$ such as solubility and mucoadhesiveness and gives rise to some interesting synergistic characteristics for use in drug delivery and tissue engineering, as well as other potentially useful biomedical properties such as anticancer, anticoagulant, antimicrobial, and cholesterol-lowering activities. ${ }^{40}$ Gao et $\mathrm{al}^{41}$ reported the synthesis of conjugate based on arginine (Arg)-grafted CS and observed a great improvement in the water solubility of CS. As an amino acid with cationic surface charge, the Arg has been reported to promote the internalization ability of Arg-grafted CS NPs through the electrostatic interaction between positively surface-charged NPs and negatively charged cell membrane. ${ }^{42}$ Park et $\mathrm{al}^{43}$ demonstrated that the conjugation of CS with Arg enhanced small interfering RNA delivery to cancer cells. In another published report, Zhu et $\mathrm{al}^{44}$ showed that Arg-modified CS improved gene transfection in HeLa cells by 100 -fold compared with the unmodified CS. 
Self-assembling block copolymers or hydrophobically modified polymers have been extensively investigated in the field of biotechnology and pharmaceuticals. ${ }^{45}$ Once hydrophobic segments are attached to the backbone of CS, the received amphiphilic conjugate could form self-assembled NPs by undergoing intermolecular association to encapsulate hydrophobic drugs and deliver drugs to the targeted sites of tumor via passive targeting. ${ }^{46}$ Amphiphilic polysaccharide derivatives are potential drug carriers because of their good cytocompatibility and biodegradability. ${ }^{47}$

Previous literature has proved that NPs based on acrylic acid derivatives such as poly(butyl cyanoacrylate) (PBCA) and monoacrylate are ideal carriers for passive drug targeting and controlled drug delivery due to their properties such as low toxicity, biodegradability, ease of synthesis, and purification. ${ }^{48-52}$ These NPs had been utilized efficiently as controlled drug delivery system for anticancer drugs, peptides, antibiotics, and analgesics. ${ }^{53-56}$ Sun et $\mathrm{al}^{57}$ demonstrated that Cur-loaded PBCA NPs result in enhanced accumulation in mice brain. In another study, Bisht et al ${ }^{52}$ reported monoacrylate-based Cur NPs for superior tumor regression compared with free Cur. Similarly, Duan et $\mathrm{al}^{58}$ reported that PBCA coated with Cur-loaded CS improves the solubility and anticancer potential of Cur against human hepatocellular carcinoma cells. Therefore, it is important and worth investigation to further explore acrylic acid-based derivatives as novel Cur carriers.

The aim of this research was to study the fabrication of self-assembled NPs based on acrylonitrile (AN) and Arg-modified CS (AN-CS-Arg) conjugate. We hypothesized that AN-CS-Arg conjugate could self-assemble to form NPs when dissolved in water and the hydrophobic Cur could be entrapped within the NPs that might lead to stabilize Cur in aqueous media. Moreover, the prolonged GIT passage at colonic mucosa offered by mucoadhesive drug delivery system will aid in sustained release of Cur within the colon. Cur-loaded AN- and Arg-modified CS NPs (AN-CS-Arg/Cur NPs) were developed by simple sonication method and evaluated for their potential as delivery system for the water insoluble drug Cur. Meanwhile, NPs were characterized for their key features such as size and morphology, zeta potential and drug-loading and encapsulation efficiency (EE). In vitro mucoadhesions were investigated. In vitro release study was carried out to study the release behavior of Cur. Furthermore, the cytotoxicity and cellular uptake in tumor cells, pharmacokinetics, and in vivo oral bioavailability of AN-CS-Arg/Cur NPs in rats were also investigated.

\section{Materials and methods Materials}

CS $\left(M_{\mathrm{n}}=50 \mathrm{kDa}\right.$, deacetylation degree of $\left.90 \%\right)$ was obtained from Laizhou Haili Biological Product Co. Ltd. (Shandong, People's Republic of China). Arg, ethyl-3-(3-dimethylaminopropyl) carbodiimide hydrochloride, $N$-hydroxysuccinimide, and sodium tripolyphosphate were procured from SigmaAldrich Co. (St Louis, MO, USA). AN (purity >99\%) was purchased from Wako Pure Chemical Industries, Ltd. (Osaka, Japan). Cur was purchased from Aladdin Chemistry Co., Ltd. (Shanghai, People's Republic of China). Pyrene was purchased from Sigma-Aldrich Co. and purified by double recrystallization from absolute ethanol. Human colorectal adenocarcinoma (HT-29) cell line was received as gift sample from Qingdao University Medical College (Qingdao, People's Republic of China). RPMI-1640 and calf serum were purchased from Hyclone Company (Utah, USA). 3-(4, 5-dimethylthiazol-2-yl)-2, 5-diphenyltetrazolium bromide (MTT) was obtained from Biomol Company (Hamburg, Germany). Dimethyl sulfoxide was received from EMD Millipore (Billerica, MA, USA). Injections of streptomycin sulfate (1 million units) and injection of sodium penicillin (800,000 units) were purchased from Shandong Lukang Pharmaceutical Co., Ltd. (Shandong, People's Republic of China). All other reagents used were of analytical grade or purer, and water was double distilled.

\section{Synthesis of AN- and Arg-modified CS conjugate}

First, CS was modified with AN (AN-CS) according to the previously published report. ${ }^{59}$ Briefly, CS was dissolved in (1 wt $\%$ ) acetic acid to form homogenous aqueous solution, afterward filtered by filter paper. The solution was neutralized with $\mathrm{NaOH}(1 \mathrm{M})$ solution with continuous stirring and the fine powder obtained was collected. Then, $\mathrm{CS}$ powder $(0.5 \mathrm{~g})$ was taken in a $100 \mathrm{~mL}$ round bottom flask and thoroughly mixed with $\mathrm{AN}(30 \mathrm{~mL})$, and $1 \mathrm{~mL}$ of aqueous $\mathrm{NaOH}$ solution $(0.6 \%)$ was mixed dropwise under magnetic stirring. This reaction was conducted at $77^{\circ} \mathrm{C}$ for 24 hours. The obtained $\mathrm{AN}-\mathrm{CS}$ was rinsed with diethyl ether and acetone.

Then, Arg was grafted on the AN-CS according to a modified method. ${ }^{60}$ Briefly, BOC-Arg(Pbf)-oH (1.05 g) and 1-ethyl-3-(3-dimethylaminopropyl) carbodiimide hydrochloride (EDC.HCl) (0.38 g) were dissolved completely in $\mathrm{N}, \mathrm{N}$-dimethyformamide (DMF) and stirred magnetically for 2 hours. $N$-hydroxysuccinimide $(0.24 \mathrm{~g})$ dissolved in DMF was added dropwise with continuous stirring. After stirring for another 4 hours, the resultant mixture was added into 
AN-CS (0.16 g) dissolved in DMF. The solution obtained was continuously stirred at room temperature for 48 hours. Trifluoroacetic acid $(1: 1 \mathrm{v} / \mathrm{v})$ was mixed into the reaction system for deprotection. Finally, the obtained solution was concentrated and precipitated in diethyl ether and dichloromethane. The yellowish powder of AN-CS-Arg was obtained and the "degree of substitution" (DS) of AN and Arg on the backbone of CS was calculated from ${ }^{1} \mathrm{H}$ nuclear magnetic resonance $\left({ }^{1} \mathrm{HNMR}\right)$ spectrum.

\section{Physicochemical characterizations of AN- and Arg-modified CS conjugate}

To demonstrate the conjugation of AN and Arg groups to the CS, Fourier transform infrared (FTIR) and ${ }^{1}$ HNMR spectroscopy methods were used. The FTIR spectra of CS and AN-CS-Arg were recorded on an FTIR Spectrophotometer430 (Jasco Company, Tokyo, Japan) following the method of Shigemasa et al. ${ }^{61}$ Approximately $2 \mathrm{mg}$ of the samples was mixed with $100 \mathrm{mg}$ of $\mathrm{KBr}$ and made into pellets for spectroscopic analysis at $20^{\circ} \mathrm{C}$. All spectra were measured over $400-4,000 \mathrm{~cm}^{-1}$.

${ }^{1} \mathrm{HNMR}$ spectra of CS and AN-CS-Arg were recorded on a ${ }^{1} \mathrm{HNMR}$ Spectrometer (Bruker AV $600 \mathrm{MHz}$; Bruker Optik GmbH, Ettlingen, Germany) using $5 \mathrm{~mm}{ }^{1} \mathrm{HNMR}$ tube

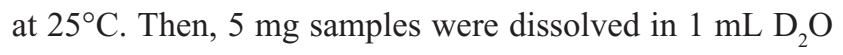
solution and ultrasonically mixed to dissolve completely, yielding a final concentration of $5 \mathrm{mg} / \mathrm{mL}$. ${ }^{1} \mathrm{HNMR}$ spectra were measured at $298 \mathrm{~K}$ with 80 scans, a spectral width of $4,800 \mathrm{~Hz}$, and a relaxation delay of 1 second between scans and acquisition time of 3.75 seconds. ${ }^{62}$

\section{Solubility test of CS and modified conjugate}

Solubility of CS and modified conjugate was estimated from turbidity. ${ }^{63}$ The pH-reliant water solubility of CS and conjugate was assessed at room temperature over a $\mathrm{pH}$ range of 2-11. Briefly, $10 \mathrm{mg}$ samples of CS and its conjugate were separately dissolved in $\mathrm{HCl}(0.1 \mathrm{M})$ solution. Then, $\mathrm{pH}$ of solution was allowed to adjust by dropwise addition of $\mathrm{NaOH}$ $(0.1 \mathrm{M})$. Finally, transmittance of solutions at $600 \mathrm{~nm}$ over selected $\mathrm{pH}$ range was observed using ultraviolet (UV)visible spectrophotometer.

\section{Measurement of fluorescence spectroscopy}

Fluorescence measurements were studied to determine the critical aggregation concentration (CAC) as described by Liu et al. ${ }^{64}$ Pyrene is one of the fluorescent probes that are widely used in the determination of CAC of surfactants and polymers since the relative intensity of the first and third emission peaks (which are denoted as $I_{1}$ and $I_{3}$ at $373 \mathrm{~nm}$ and $393 \mathrm{~nm}$, respectively) is a good marker of environment polarity. ${ }^{65}$ At a concentration of $0.4 \mathrm{mg} / \mathrm{mL}$, purified pyrene was dissolved in ethanol. Approximately $20 \mu \mathrm{L}$ of the resulting solution was added into a $20 \mathrm{~mL}$ test tube and ethanol was driven off under the stream of nitrogen gas. Then, $10 \mathrm{~mL}$ of AN-CS-Arg NPs solution was subsequently added to the test tube, bringing the final concentration of pyrene to $2 \mu \mathrm{M}$. The mixture was incubated for 3 hours in a water bath at $65^{\circ} \mathrm{C}$ and shaken in a SHA-B shaking water bath (Guo Hua Company, Jintan, Jiangsu, People's Republic of China) overnight at $20^{\circ} \mathrm{C}$. Using a RF-5301PC Fluorescence Spectrophotometer (Shimadzu, Kyoto, Japan), pyrene emission spectra were obtained. Both emission and excitation slits were set to $10 \mathrm{~nm}$ and $2.5 \mathrm{~nm}$, respectively. ${ }^{66}$ Plot of $I_{1} / I_{3}$ vs log concentration was drawn, and the concentration at which sudden increase in $I_{1} / I_{3}$ had been occurred was considered as CAC value.

\section{Preparation of Cur-loaded AN- and Arg- modified CS NPs}

Cur-loaded AN- and Arg-modified CS NP (AN-CS-Arg/ Cur NPs) solution was synthesized using sonication method, similar to that employed by Lee et al. ${ }^{67}$ First, $10 \mathrm{mg} / \mathrm{mL}$ of Cur ethanol solution was prepared. Then, AN-CS-Arg conjugate $(20 \mathrm{mg})$ was dissolved into $10 \mathrm{~mL}$ distilled water and ultrasonically mixed. To this solution, Cur ethanol solution was added, placed in ice bath, and sonicated at $90 \mathrm{~W}$ for 2 minutes. This was repeated three times to make AN-CSArg/Cur NPs solution. In the process of this fabrication, Cur occupied the hydrophobic cores of NPs to form AN-CS-Arg/ Cur NPs. The obtained solution was then transferred into a pre-swollen membrane with a molecular weight cutoff of $1,200 \mathrm{kDa}$ and dialyzed against $40 \mathrm{~mL}$ of $5 \%$ ethanol for 48 hours during which the dialysate was changed three times to remove the unloaded Cur, ethanol, and other impurities, and thereafter, lyophilized and stored at $4^{\circ} \mathrm{C}$ for further use. Similarly, blank NPs without Cur were prepared, keeping the rest of the method the same. Figure 1 shows schematic drawing of self-assembled AN-CS-Arg/Cur NPs. The hydrophobic Cur occupies the hydrophobic core while Arg forms the outer hydrophilic shell.

\section{Particle size and morphology}

AN-CS-Arg/Cur NPs were characterized for size and morphology using an EM 400 transmission electron microscopy (TEM; Philips, Eindhoven, the Netherlands) operating at accelerating voltage of $80 \mathrm{kV}$. Five to ten drops of sample 


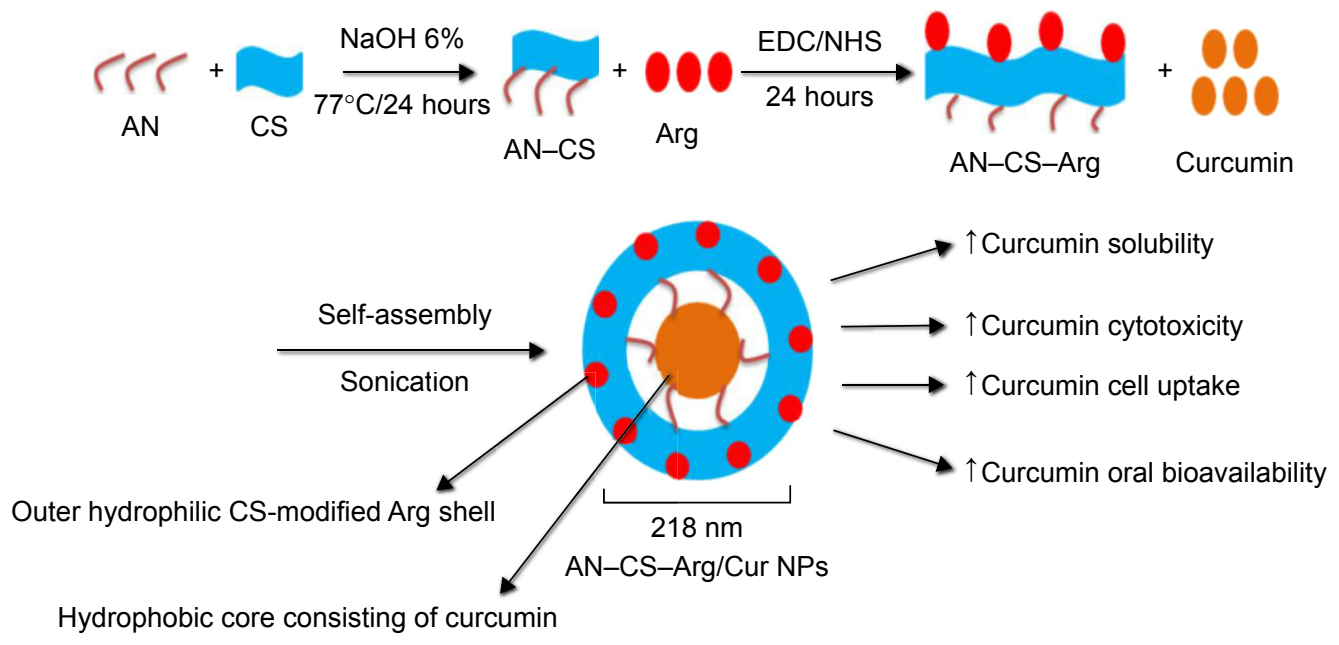

Figure I Schematic drawing of self-assembled Cur-encapsulated AN-CS-Arg NPs. Abbreviations: AN, acrylonitrile; Arg, arginine; CS, chitosan; Cur, curcumin; EDC, ethyl-3-(3-dimethylaminopropyl) carbodiimide hydrochloride; NHS, N-hydroxysuccinimide; NPs, nanoparticles.

solution were carefully placed onto a carbon-coated copper grid, followed by the removal of excess solution by blotting the grid with filter paper. The samples were dried for 72 hours at room temperature. Afterward, the samples were stained negatively using phosphotungstic acid (2\%) and allowed to dry further for 72 hours before final observation.

\section{Particle size and zeta potential}

The size distribution, mean particle size, and polydispersity index (PDI) of the AN-CS-Arg/Cur NPs were determined at room temperature by dynamic light scattering using a nano-ZS Zetasizer (Malvern Instruments, Malvern, UK). The concentration of the NPs solution was kept at $1 \mathrm{mg} / \mathrm{mL}$ and measurements were performed three times. All measurements were performed at the wavelength of $635 \mathrm{~nm}$ with a fixed scattering angle of $90^{\circ}$.

Zeta potential deals with the stability of formulations and is an indicator for charge present on the surface of NPs. A nano-ZS Zetasizer was used to measure the zeta potential of NPs. Each sample was analyzed in triplicate at $25^{\circ} \mathrm{C}$, and the average of three readings was reported.

\section{EE and LE of Cur-loaded AN- and Arg- modified CS NPs}

The EE and loading efficiency (LE) of the synthesized NPs were determined by measuring the concentration of free Cur in the dispersion medium by centrifugation at $16,000 \times \mathrm{g}$ for 20 minutes. The supernatant obtained was diluted with $90 \%$ ethanol, and the drug concentration in the resultant solution was measured at $420 \mathrm{~nm}$ by high-performance liquid chromatography (HPLC; Agilent Technologies, Santa Clara, CA, USA) with a standard curve. The HPLC analysis was carried out on a reversed phase $\mathrm{C} 18$ column $(4.6 \times 150 \mathrm{~mm}, 5 \mu \mathrm{m}$, ZORBAX Eclipse XDB-C18) with a mobile phase composed of methanol and $0.3 \%$ acetic water solution $(80: 20 \mathrm{v} / \mathrm{v})$ at a flow rate of $1 \mathrm{~mL} / \mathrm{min}$. The following formulas were used to calculate the $\mathrm{EE}$ and LE.

$$
\begin{gathered}
\mathrm{EE}=\frac{\text { Total curcumin }- \text { Free curcumin }}{\text { Total curcumin }} \times 100 \% \\
\mathrm{LE}=\frac{\text { Total curcumin }- \text { Free curcumin }}{\text { Weight of freeze-dried nanoparticles }} \times 100 \%
\end{gathered}
$$

where the free Cur is the analyzed weight of drug in supernatant, total Cur is the feeding weight of drug in the preparation of NPs, and the weight of freeze-dried NPs is the total weight of carrier.

\section{In vitro drug release study}

The release property of Cur from AN-CS-Arg/Cur NPs was assessed by dialysis. Free Cur solution $(5 \mathrm{mg} / \mathrm{mL}$ dissolved in $90 \%$ ethanol) with the same concentration was considered as control. Solutions of $2.5 \mathrm{~mL}$ AN-CS-Arg/Cur NPs or free Cur with Cur concentration of $0.2 \mathrm{mg} / \mathrm{mL}$ were transferred into dialysis bags (molecular weight cutoff, $6-8 \mathrm{kDa}$ ) and dialyzed against $10 \mathrm{~mL}$ release medium at different $\mathrm{pH}$ values (0.05 M glycine-hydrochloric acid buffer at $\mathrm{pH} 2.0,0.05 \mathrm{M}$ phosphate buffer at $\mathrm{pH} 5.0$, and $0.05 \mathrm{M}$ phosphate buffer at $\mathrm{pH}$ 6.8). To prevent the degradation of the released Cur, ascorbic acid at a concentration of $1 \%$ and butylated hydroxytoluene at a concentration of $0.1 \%$ were added into the buffer solutions. ${ }^{68}$ Then, the release medium was continuously stirred at $37^{\circ} \mathrm{C}$ for 72 hours. At predetermined interval, 
$3.0 \mathrm{~mL}$ of sample was drawn out and replenished with $3.0 \mathrm{~mL}$ fresh buffer. The amount of released Cur was measured by the curve of concentration values obtained using HPLC method as described earlier and the following formula. All the release experiments were performed three times.

$$
\text { Release }(\%)=\frac{\text { Released curcumin }}{\text { Total curcumin }} \times 100
$$

\section{Ex vivo mucoadhesion measurements}

All animal experiments were performed in accordance with the European community council directive of September 22, 2010 (2010/63/EU). The mucoadhesion experiment was conducted according to the previously published method. ${ }^{69}$ Male Sprague Dawley rats (180-220 gm) were purchased from Qingdao Coastal Institute for Drug Control, Qingdao, People's Republic of China. After obtaining ethical approval from the Animal Care and Use Committee of the Ocean University of China, the rats were sacrificed in $\mathrm{CO}_{2}$ chamber. The excised colon from rats was washed thoroughly with ice-cold phosphate-buffered saline to remove all its contents. Approximately $6 \mathrm{~cm}$ colon segments were cut open and everted with the help of tweezers and glass rod. One end was closed with closure, and the sac was filled through the other open end with $1 \mathrm{~mL}$ medium Dulbecco's Modified Eagle Medium: Nutrient Mixture F-12 (DMEM: F12). Afterward, the open end was also closed and kept at $4^{\circ} \mathrm{C}$ for further use. The sac was then suspended in a centrifuge tube $(15 \mathrm{~mL})$ containing $5 \mathrm{mg}$ of the synthesized NP suspension dispersed in $5 \mathrm{~mL}$ of the same medium. Thereafter, the tube was gently agitated at $37^{\circ} \mathrm{C}$ for 60 minutes to assure the attachment equilibrium. Then, the tube was removed and centrifuged for the recovery of NPs that did not attach to colon. The amount obtained was subtracted from the initial amount of NPs added to the system to know the exact amount of NPs attached to the colon. To represent the loss of colonic tissue in experiment, the sac was incubated in NPs-free medium and used as a control. Similar procedure was carried out for CS NPs (prepared by dropwise addition of tripolyphosphate to acidic CS solution at 1:3 w/w), and the average of three results is reported in this article.

\section{In vitro cytotoxicity study}

To investigate the in vitro cytotoxicity, human colorectal adenocarcinoma (HT-29) cell lines were obtained from the cell bank of Qingdao University Medical College, Qingdao, People's Republic of China. HT-29 cells were then grown in RPMI-1640 medium supplemented with penicillin and streptomycin (1\%) and fetal bovine serum (10\%). The cells were seeded at a density of $3-5 \times 10^{4}$ cells/well into a 96-well plate and cultured in a humid atmosphere at $37^{\circ} \mathrm{C}$ having $5 \%$ $\mathrm{CO}_{2}$ gas. After culturing for 24 hours, cytotoxicities of blank AN-CS-Arg NPs and AN-CS-Arg/Cur NPs were evaluated in HT-29 cells by the (MTT) dye assay method. ${ }^{70,71}$ Using microplate reader, the UV absorbance intensity was measured at $490 \mathrm{~nm}$. All the experiments were performed in triplicate, and the cell viability is expressed by the following equation:

$$
\text { Cell viability }(\%)=\frac{\text { Abs sample }}{\text { Abs control }} \times 100
$$

where Abs sample is the absorbance intensity of the cells treated with blank AN-CS-Arg NPs, Cur solution, or ANCS-Arg/Cur NPs and Abs control is the absorbance intensity of untreated cells.

\section{Intracellular uptake study}

To examine the cellular uptake of unmodified Cur and ANCS-Arg/Cur NPs, the fluorescence microscopic study was performed using HT-29 cells. Briefly, HT-29 cells at a density of $2.5 \times 10^{4}$ cells/well were seeded into a six-well plate. After overnight incubation in a humid environment with $5 \% \mathrm{CO}_{2}$ at $37^{\circ} \mathrm{C}$, cells were treated with a medium containing free Cur or AN-CS-Arg/Cur NPs (the concentration of Cur was $0.02 \mathrm{mg} / \mathrm{mL}$ ). After incubation for 2 hours, the cells were rinsed three times with phosphate-buffered saline at $37^{\circ} \mathrm{C}$ to eliminate Cur or AN-CS-Arg/Cur NPs that were not taken up by the cells. Then, the cells were imaged under a Nikon ECLIPSE TE 2000-U Fluorescence Microscope (20× objective) equipped with a digital camera and a blue filter (420-490 nm excitation, 490-560 nm emission). Images were captured with NIS Elements F 3.0 software (Nikon Corporation, Tokyo, Japan).

\section{In vivo oral administration and pharmacokinetics}

Twelve male Sprague Dawley rats (220-250 g) were purchased from Qingdao Coastal Institute for Drug Control, Qingdao, People's Republic of China and cared in air-conditioned quarters under a photoperiod schedule of 12-hour light/dark cycle. They were allowed to receive laboratory chow and tap water available ad libitum for 7 days. All the animal experiments were performed in accordance with the European Community Council Directive of September 22, 2010 (2010/63/ EU). Experimental rats were first anesthetized with $0.5 \mathrm{~mL}$ chloral hydrate (10\%). Then, divided into two groups; the first group also called the control group $(n=6)$ was given aqueous 
solution of free Cur with $10 \%$ ethanol mixture; the second group ( $\mathrm{n}=6)$ received $\mathrm{AN}-\mathrm{CS}-\mathrm{Arg} / \mathrm{Cur}$ NPs solution. The Cur dosage for both the experimental and control group was $100 \mathrm{mg} / \mathrm{kg}$ body weight and administered once by oral gavages, after blood samples $(0.3 \mathrm{~mL})$ from the jugular vein were collected into microcentrifuge tubes containing $200 \mu \mathrm{L}$ of ethylenediaminetetraacetic acid-K2 solution and replenished with $400 \mu \mathrm{L}$ heparin saline at fixed time intervals. The plasma was collected by centrifuging the blood sample at 4,000 rpm for 20 minutes. For protein precipitation, $200 \mu \mathrm{L}$ of $99 \%$ ethanol was mixed to $200 \mu \mathrm{L}$ of plasma. Subsequently, $10 \mu \mathrm{L}$ $(1 \mathrm{mg} / \mathrm{mL}) \beta$-17-estradiol acetate in ethyl acetate was added as the internal standard. Then, extraction with ethyl acetate was carried out for three times and redissolved in $\mathrm{H}_{2} \mathrm{O}$ :acetonitrile $(1: 2 \mathrm{v} / \mathrm{v})$ mixture. The samples were vortexed and centrifuged at $1,000 \times g$ for 30 minutes. Then, $200 \mu \mathrm{L}$ of supernatants was separated and processed for pharmacokinetic analysis using reversed-phase (RP)-HPLC as described earlier with the help of statistics calculated on DAS 2.1.1 software designed by Chinese Pharmacological Society.

\section{Statistical analysis}

All the results were expressed using Microsoft Excel 2013, Graph pad Prism 6.01, and DAS 2.1.1 softwares, and the chemical structure was processed by ChemDraw 7.0. The assays were formed in triplicate on separate occasions.
Results were expressed as mean value \pm standard deviation. Differences were considered to be statistically significant when the $P$-values were $<0.05$.

\section{Results and discussion Synthesis and structural characterization of AN- and Arg-modified CS conjugate}

The synthetic route of AN-CS-Arg was shown in figure 2. Both the groups were conjugated on the backbone of CS. The hydroxyl group present in CS was reacted with carbon-carbon double bond $(\mathrm{HC}=\mathrm{CH})$ in $\mathrm{AN}$. The protected $\mathrm{Arg}$ was grafted on CS via amide bond formation, and the deprotection was carried out to get AN-CS-Arg. This modification had many advantages. The first advantage was the improvement in the solubility of CS after AN modification, the AN-modified CS was soluble in organic solvents, which was feasible for the following step of Arg grafting. Moreover, the modified CS was amphiphilic in behavior, which could undergo through self-assembly to form NPs. The second advantage was the improvement in the transmembrane ability of the modified CS NPs, as Arg has been reported to be the main component in cell-penetrating peptides.

FTIR spectra of CS and modified CS conjugate are shown in Figure 3. It was clear that a characteristic strong peak of $\mathrm{C} \equiv \mathrm{N}$ emerged at $2,257.39 \mathrm{~cm}^{-1}$. It showed that AN was successfully grafted on the backbone of CS. The second new
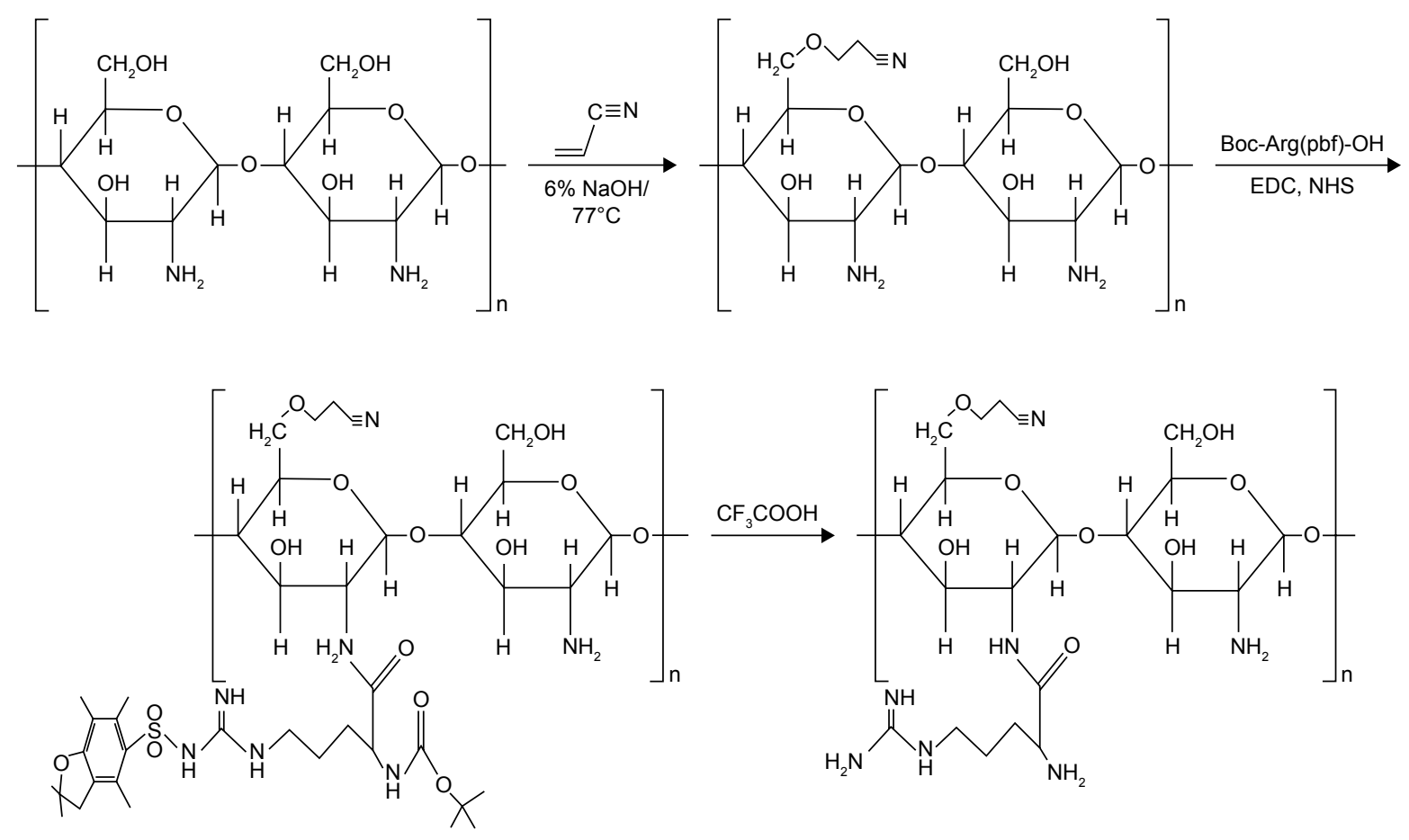

Figure 2 Process and structure of AN- and Arg-modified CS (AN-CS-Arg) synthesis.

Abbreviations: AN, acrylonitrile; Arg, arginine; CS, chitosan; EDC, ethyl-3-(3-dimethylaminopropyl) carbodiimide hydrochloride; NHS, N-hydroxysuccinimide. 


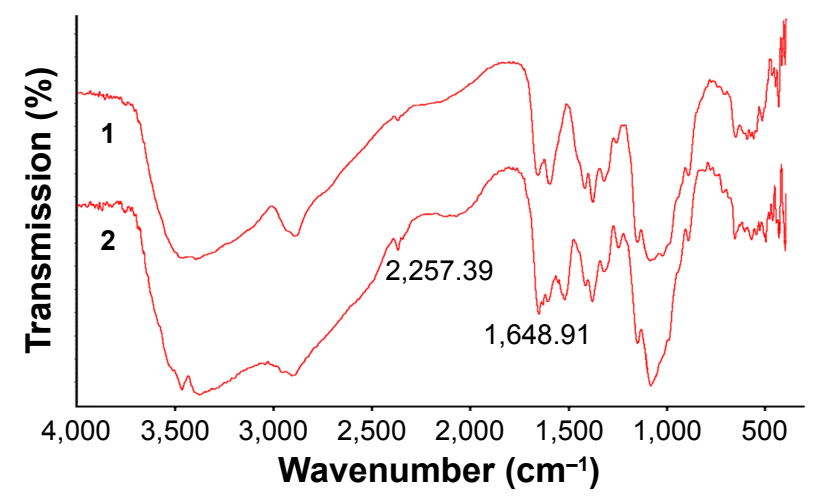

Figure 3 FTIR spectra of (I) CS (2) AN- and Arg-modified CS (AN-CS-Arg) conjugate.

Abbreviations: AN, acrylonitrile; Arg, arginine; CS, chitosan; FTIR, Fourier transform infrared.

and strong peak at $1,648.91 \mathrm{~cm}^{-1}$ could be attributed to the amide bond formation between CS and Arg.

The successful incorporation of the AN and Arg groups was further ascertained by ${ }^{1} \mathrm{HNMR}$ assay of $\mathrm{CS}$ and ANCS-Arg conjugate (Figure 4). The ${ }^{1}$ HNMR spectrum of CS is illustrated in the inset picture of Figure 4, in which the concentrated chemical shift from $2.2 \mathrm{ppm}$ to $4.7 \mathrm{ppm}$ was due to the chemical environment of the protons in CS chains. Figure 4 depicts the ${ }^{1} \mathrm{HNMR}$ spectrum of AN-CS-Arg conjugate in which the additional peaks from $\sim 1.1 \mathrm{ppm}$ to $2.0 \mathrm{ppm}$ clearly indicated the conjugation of $\mathrm{AN}$ and Arg groups to the backbone of CS. The characteristic protons of e and $\mathrm{f}$ (Figure 4) in AN moiety and a and din Arg appeared at $\sim 1.6 \mathrm{ppm}$ and characteristic protons in $\mathrm{CH}_{2} \mathrm{CH}_{2}$ (b and c) unit were observed at $\sim 1.1 \mathrm{ppm}$ and $1.2 \mathrm{ppm}$, respectively. The DS of AN and Arg on CS chains as calculated via the calculation from ${ }^{1} \mathrm{HNMR}$ spectra was $2.5 \%$ and $2.8 \%$, respectively. The DS was calculated by using the following formula:

$$
\begin{aligned}
& \mathrm{DS}= \\
& \frac{\text { Integrity of protons in } \mathrm{CH}_{2} \mathrm{CH}_{2}(\mathrm{~b} \text { and c) unit } / 4}{\text { Integrity of protons in } \mathrm{CS} / 7} \times 100 \%
\end{aligned}
$$

On the basis of FTIR and ${ }^{1} \mathrm{HNMR}$ spectra of CS and ANCS-Arg samples, both AN and Arg have been successfully grafted on CS main chains.

\section{Solubility of CS and modified conjugate at $\mathrm{pH} 2-\mathrm{II}$}

The solubility of CS and modified conjugate measured by transmittance as function of $\mathrm{pH}$ values in aqueous solution is

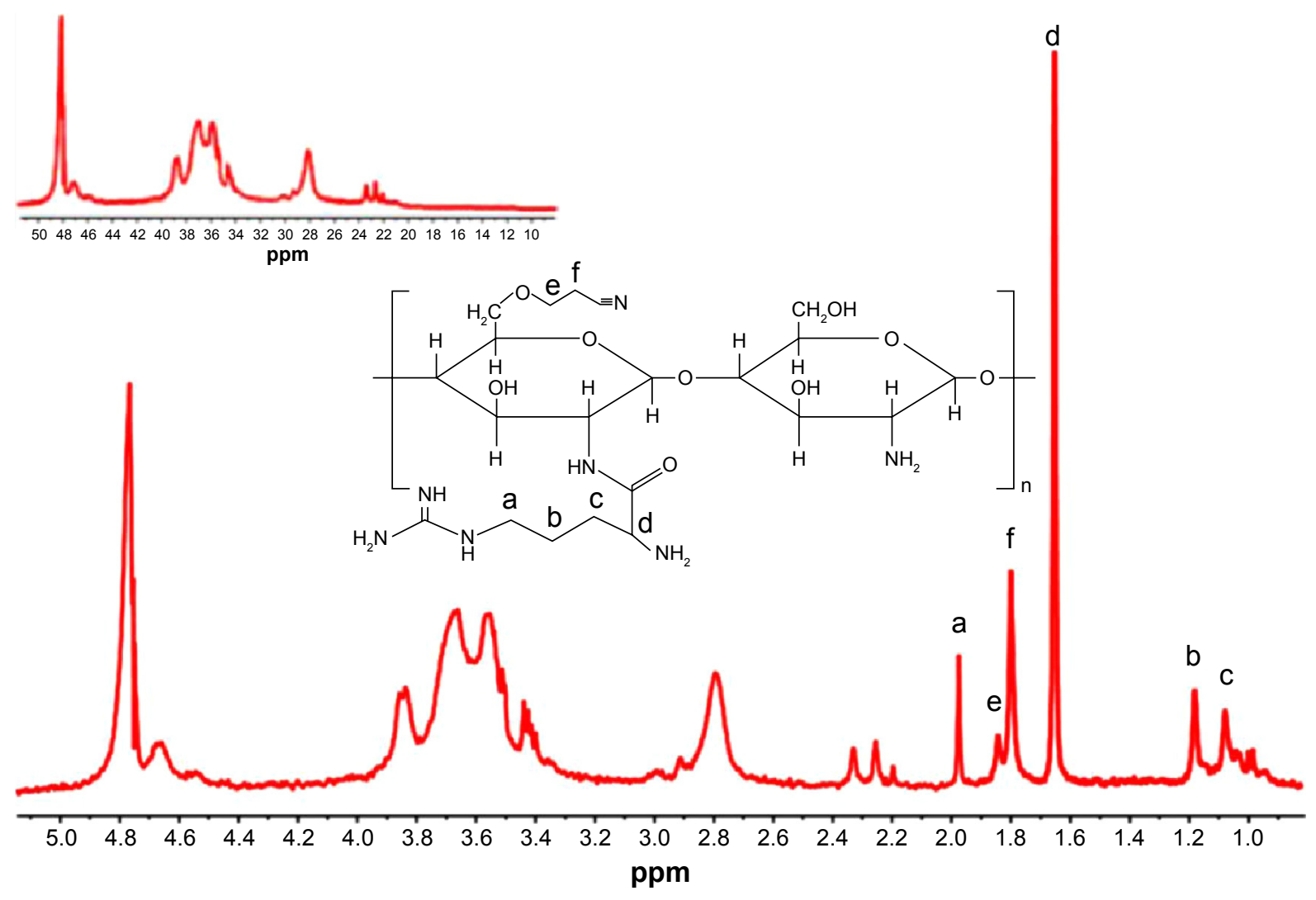

Figure 4 'HNMR spectrum of AN-CS-Arg conjugate (inset: 'HNMR spectrum of CS).

Notes: a, b, c and d represent characteristic protons in Arg moiety; e and f represent characteristic protons in AN moiety.

Abbreviations: AN, acrylonitrile; Arg, arginine; CS, chitosan; 'HNMR, 'H nuclear magnetic resonance; ppm, parts per million. 


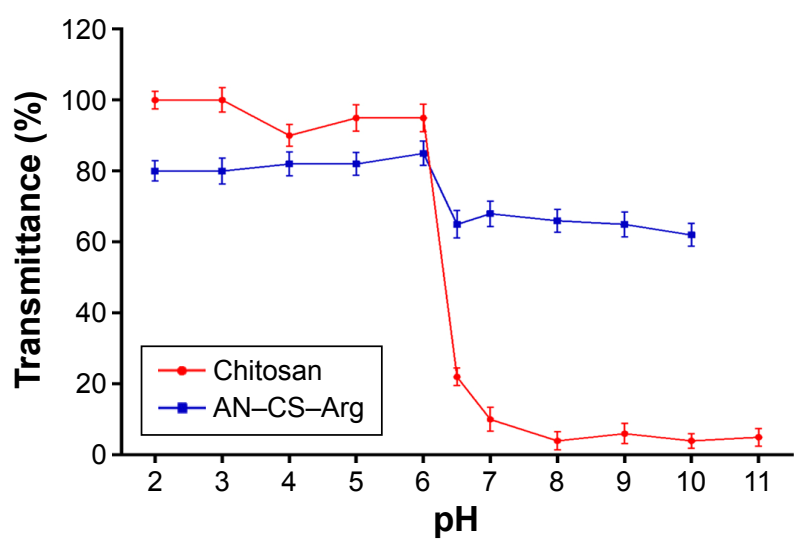

Figure 5 Solubility of CS and AN-CS-Arg conjugate.

Note: Data are expressed as mean \pm SD $(n=3)$.

Abbreviations: AN, acrylonitrile; Arg, arginine; CS, chitosan; SD, standard deviation.

shown in Figure 5. The turbidity of CS solution as measured by relative transmittance was remarkably decreased from its original value, $100 \%$ to $90 \%$ at $\mathrm{pH} 2-6$ downward to $22 \%$ to $2.9 \%$ at $\mathrm{pH} 6.5-11$. On the contrary, the modified CS showed an improved solubility over the entire tested $\mathrm{pH}$ range. This result is consistent with the previous published reports. ${ }^{72,73}$

\section{Self-aggregates of AN- and Arg-modified CS in solution}

Fluorescence spectroscopy was used to determine the rheology of AN-CS-Arg in aqueous media. The variation of fluorescence intensity ratio for peak I/III against the logarithm of AN-CS-Arg concentration was shown in Figure 6. At low concentrations $(0.0001-0.01 \mathrm{mg} / \mathrm{mL})$, the intensity ratios of peak I/III remain fairly constant. However, as AN-CS-Arg concentration increased from $0.075 \mathrm{mg} / \mathrm{mL}$ to $1 \mathrm{mg} / \mathrm{mL}$, the intensity ratio decreased significantly. The concentration corresponding to the breakpoint shown in Figure 6 was the

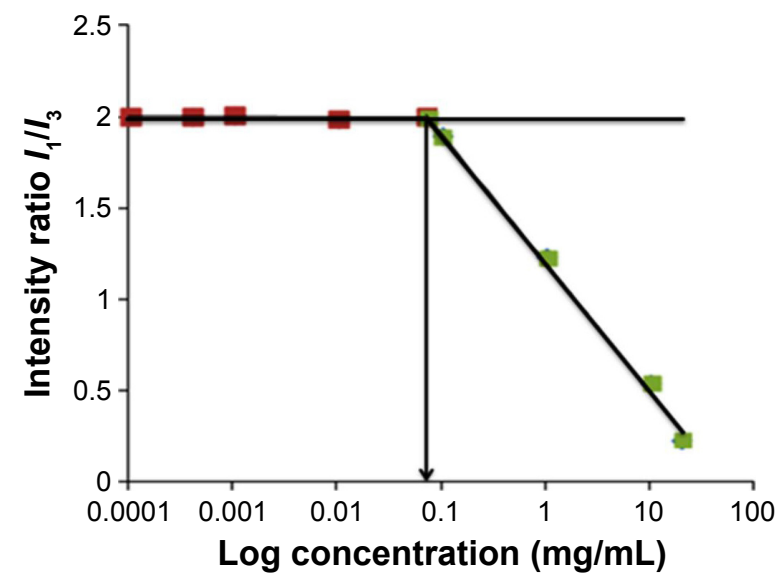

Figure 6 The variation of fluorescence intensity ratio $I_{1} / I_{3}$ against the logarithm of AN-CS-Arg conjugate concentration in distilled water.

Abbreviations: AN, acrylonitrile; Arg, arginine; CS, chitosan.
CAC value of AN-CS-Arg, which was $\sim 0.081 \mathrm{mg} / \mathrm{mL}$. The low CAC value indicated that AN-CS-Arg NPs could be formed at a low copolymer concentration.

\section{Characterization of self-assembled Cur- loaded AN- and Arg-modified CS NPs Morphology, particle size, PDI, and zeta potential} The size and morphology of the prepared NPs were confirmed by TEM. Figure 7 shows the TEM image of AN-CS-Arg/ Cur NPs, indicating spherical particles within an average size range of $218 \mathrm{~nm}$.

Particle size is a very important parameter for drug delivery carriers. It has been reported that particles smaller than $1 \mu \mathrm{m}$ can undergo capillary distribution and uniform perfusion at the desired target site. ${ }^{74}$ Most solid tumors have high levels of vascular permeability. Particles $<400 \mathrm{~nm}$ can cross vascular endothelia and accumulate at the tumor site via the enhanced permeability and retention (EPR) effect. ${ }^{75,76}$ Figure 8A reveals the size distribution of AN-CS-Arg/Cur NPs solution prepared under sonication. The particle size of AN-CS-Arg/Cur NPs obtained under ultrasound condition was found to be $218 \mathrm{~nm}$ and PDI was $0.325 \pm 0.027$ which indicated a narrow particle size distribution with better effect.

The zeta potential of the NPs as measured and graphed in Figure $8 \mathrm{~B}$ was $40.1 \pm 2.81 \mathrm{mV}$, which should be ascribed to the positive charge, arisen from CS units. The size and zeta potential of NPs are critical parameters for cellular uptake. It has been reported that positively charged surfaces facilitate adhesion of the NPs to negatively charged cellular membranes, which may improve their potential as drug delivery

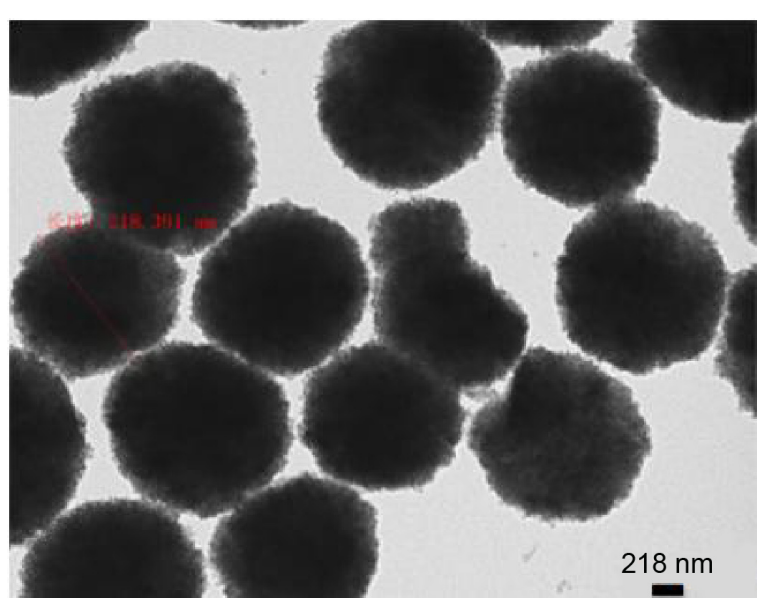

Figure 7 TEM image of AN-CS-Arg/Cur NPs solution.

Note: TEM image of AN-CS-Arg/Cur NPs solution at magnification $(100,000 \times)$, scale bar represent $218 \mathrm{~nm}$.

Abbreviations: AN, acrylonitrile; Arg, arginine; CS, chitosan; Cur, curcumin; NPs, nanoparticles; TEM, transmission electron microscopy. 

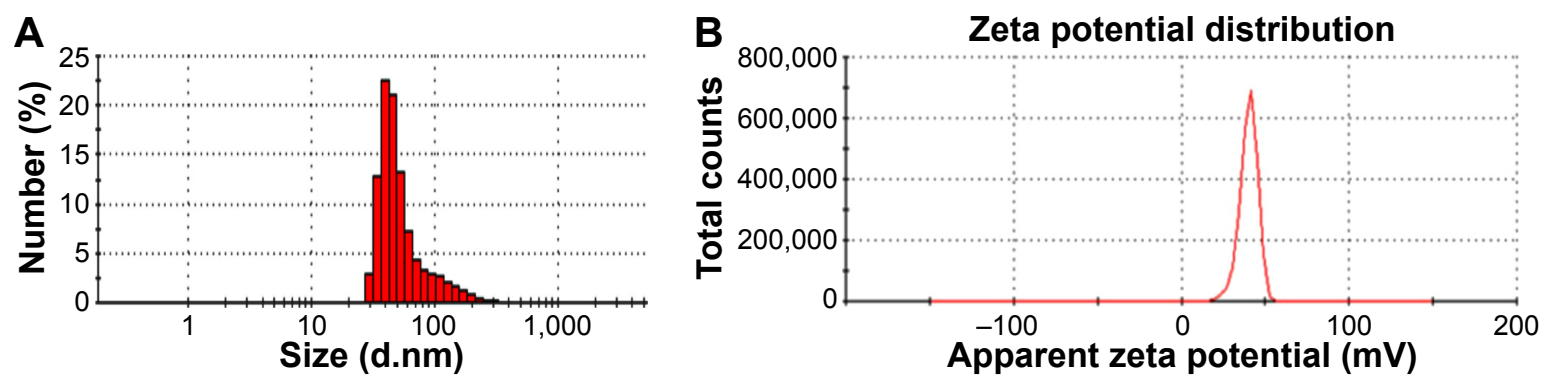

Figure 8 (A) Size distribution of I mg/mL AN-CS-Arg/Cur NPs solution. (B) Zeta potential of I mg/mL AN-CS-Arg/Cur NPs solution. Abbreviations: AN, acrylonitrile; Arg, arginine; CS, chitosan; Cur, curcumin; NPs, nanoparticles.

carriers. ${ }^{77}$ The prepared NPs possess positive surface charge and are suitable to be used as drug delivery carrier.

A comparative effect of Cur concentration on particle size, PDI, and zeta potential is presented in Table 1 . With increasing amounts of Cur in the formulation, the particle size was reduced from $218.3 \pm 7.2 \mathrm{~nm}$ to $185.3 \pm 5.9 \mathrm{~nm}$ and the values of PDI decreased from $0.325 \pm 0.027$ to $0.290 \pm 0.012$, while no significant effect was observed on zeta potential values. The reduction in size with increasing concentration of Cur might be due to the formation of denser and stronger hydrophobic core. Earlier studies with other types of Cur-encapsulated nanoparticulates demonstrated similar results. ${ }^{78}$

\section{Drug EE and drug loading}

AN- and Arg-modified CS NPs (AN-CS-Arg/Cur NPs) were successfully used to encapsulate the hydrophobic Cur inside the hydrophobic core. As the concentration of Cur increased, the LE increased from $6.48 \% \pm 0.27 \%$ to $27.82 \% \pm 2.55 \%$, whereas the EE decreased from $76.53 \% \pm 3.58 \%$ to $66.34 \% \pm 3.12 \%$ as shown in Table 2 .

Furthermore, it is obvious from Table 2 that with increasing concentration of Cur, EE and LE increase but when the concentration becomes $>8 \mathrm{mg}$ EE declines. This might be due to the reason that the carrying capacity of AN-CS-Arg conjugate is limited; when the concentration reaches to some

Table I Characterization of AN-CS-Arg/Cur NPs by varying drug concentration

\begin{tabular}{lllll}
\hline $\begin{array}{l}\text { Cur } \\
\text { formulation }\end{array}$ & $\begin{array}{l}\text { Cur } \\
(\mathbf{m g})\end{array}$ & $\begin{array}{l}\text { Size } \\
(\mathbf{n m})\end{array}$ & PDI & $\begin{array}{l}\text { Zeta potential } \\
(\mathbf{m V})\end{array}$ \\
\hline $\begin{array}{l}\text { AN-CS-Arg/ } \\
\text { Cur NPs I }\end{array}$ & 5 & $218.3 \pm 7.2$ & $0.325 \pm 0.027$ & $40.1 \pm 2.8 \mathrm{I}$ \\
$\begin{array}{l}\text { AN-CS-Arg/ } \\
\text { Cur NPs 2 }\end{array}$ & 8 & $199.4 \pm 6.3$ & $0.310 \pm 0.015$ & $36.3 \pm 2.65$ \\
$\begin{array}{l}\text { AN-CS-Arg/ } \\
\text { Cur NPs 3 }\end{array}$ & 10 & $185.3 \pm 5.9$ & $0.290 \pm 0.012$ & $39.4 \pm 1.52$ \\
\hline
\end{tabular}

Note: Data are expressed as mean \pm SD.

Abbreviations: Arg, arginine; AN, acrylonitrile; CS, chitosan; Cur, curcumin; NPs, nanoparticles; PDI, polydispersity index; SD, standard deviation. point, then more Cur will be buried into the hydrophobic microdomains of AN-CS-Arg/Cur NPs but the drug-loading amount will increase with the increase in feeding amount of Cur. ${ }^{79,80}$ Formulation 2 was selected in the remainder of experimental studies due to optimized properties.

Entrapment efficiency and LE of Cur in AN-CS-Arg/Cur NPs were found to be $76.53 \% \pm 3.58 \%$ and $27.82 \% \pm 2.55 \%$, respectively, as mentioned earlier. These results are consistent with the previous findings in reports ${ }^{74-76,81}$ and also suggest that the concentration of Cur and AN-CS-Arg can be adjusted to give desired entrapment efficiency and LE.

\section{Aqueous solubility study}

Cur immediately precipitates in water as practically having an extremely low aqueous solubility, but a significant enhancement in its aqueous solubility was observed after encapsulation into AN-CS-Arg NPs. While maintaining clear and transparent appearance, the solubility of Cur in water was largely enhanced from the original $11 \mathrm{ng} / \mathrm{mL}^{82}$ to $0.5 \mathrm{mg} / \mathrm{mL}$ after encapsulation into AN-CS-Arg NPs, $\sim 5 \times 10^{4}$-fold increase. These results indicated that the obtained NPs system could significantly improve the solubility of Cur in aqueous solution, and the images shown in Figure 9 support the fact. The main reason for the low oral bioavailability of Cur is its insolubility in aqueous solutions, and many of researchers are

Table 2 EE and LE of AN-CS-Arg/Cur NPs with increasing amount of Cur added

\begin{tabular}{llll}
\hline $\begin{array}{l}\text { Cur } \\
\text { formulation }\end{array}$ & $\begin{array}{l}\text { Cur } \\
(\mathbf{m g})\end{array}$ & EE (\%) & LE (\%) \\
\hline $\begin{array}{l}\text { AN-CS-Arg/ } \\
\text { Cur NPs I }\end{array}$ & 5 & $57.24 \pm 2.73$ & $6.48 \pm 0.27$ \\
$\begin{array}{l}\text { AN-CS-Arg/ } \\
\text { Cur NPs 2 }\end{array}$ & 8 & $76.53 \pm 3.58$ & $14.23 \pm 1.65$ \\
$\begin{array}{l}\text { AN-CS-Arg/ } \\
\text { Cur NPs 3 }\end{array}$ & 10 & $66.34 \pm 3.12$ & $27.82 \pm 2.55$ \\
\hline
\end{tabular}

Note: Data are expressed as mean $\pm S D$.

Abbreviations: Arg, arginine; AN, acrylonitrile; CS, chitosan; Cur, curcumin; EE, encapsulation efficiency; LE, loading efficiency; NPs, nanoparticles; SD, standard deviation. 


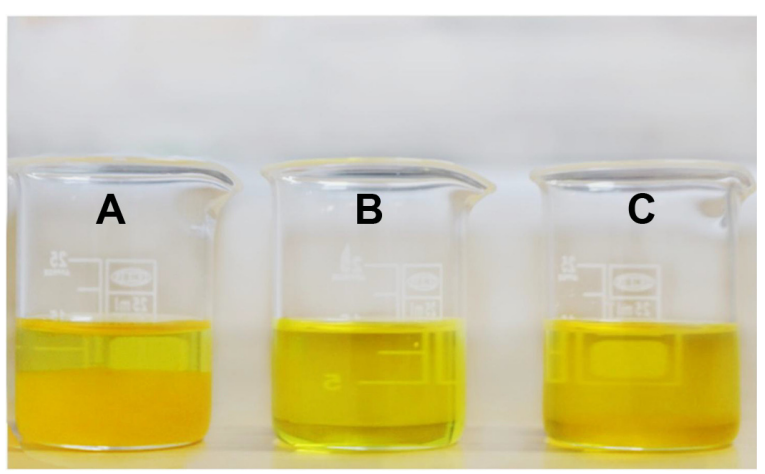

Figure 9 Images of free Cur and AN-CS-Arg/Cur NPs solution.

Notes: (A) Images of free Cur solution; (B) AN-CS-Arg/Cur formulated as lyophilized powder of $0.2 \mathrm{mg} / \mathrm{ml}$ Nps solution; and (C) AN-CS-Arg/Cur formulated as lyophilized powder of $0.5 \mathrm{mg} / \mathrm{ml} \mathrm{Nps} \mathrm{solution;} \mathrm{in} \mathrm{water} \mathrm{at} \mathrm{pH} 7.4$, clearly showing the enhanced solubility of Cur, while maintaining clear and transparent appearance but free Cur forms flakes indicating poor solubility.

Abbreviations: AN, acrylonitrile; Arg, arginine; CS, chitosan; Cur, curcumin; NPs, nanoparticles.

interested in how to improve the solubility of Cur. We can say that an increase in Cur solubility from these NPs may be due to the combination of hydrophobic microenvironment of Cur and the solubilizing effect of the carrier. ${ }^{58,83,84}$

\section{In vitro release study}

Cur has been well reported for the hasty elimination in the metabolism process. ${ }^{82,85}$ Nanocarrier-based delivery may provide an alternative approach to shield Cur from metabolic degradation before Cur reaches to its targeted site of action. To achieve this goal, sustained release of Cur is required. ${ }^{86}$

The release profiles of AN-CS-Arg/Cur NPs were obtained in three media at $\mathrm{pH} 2.0, \mathrm{pH} 5.0$, and $\mathrm{pH} 6.8$, simulating various physiological environments. The different three $\mathrm{pH}$ values were chosen to simulate different physiological environments, including stomach $(\mathrm{pH}$ 1.0-2.5), intestine ( $\mathrm{pH}$ 6.4-7.5), intracellular components (pH 4.5-8.0), and solid tumor extracellular microenvironment ( $\mathrm{pH} \sim 6.5$ ). As shown in Figure 10, Cur was released much slower after being encapsulated by AN-CS-Arg NPs compared with free Cur, which reveals the sustained release of AN-CS-Arg/Cur NPs. For example, after 72 hours, 57\%, $50 \%$, and $63 \%$ of the Cur were released from the AN-CSArg NPs at $\mathrm{pH} 2.0, \mathrm{pH} 5.0$, and $\mathrm{pH} 6.8$, respectively; by contrast, native Cur had completed its release/diffusion at the three pHs studied. It suggests that the AN-CS-Arg/Cur NPs can be used as sustained formulations applied either in oral administration or in intravenous administration. The release mechanism from the NPs might be related to the diffusion of drug and disintegration of polymer. ${ }^{87,88}$ The drug release process was mainly as follows: first, the media gradually diffused into the interior NPs (hydrophobic core) to dissolve Cur and the dissolved drug spread to the media slowly. Then, the carrier was degraded and the Cur was released with a slow rate. ${ }^{89}$ To investigate the release mechanism of Cur from AN-CS-Arg/Cur NPs, we analyzed regression coefficients with three kinetic models (first-order, zero-order, and Higuchi model). As a result, the Higuchi's square-root plot was best fitted with release kinetic with regression coefficients $\left(R^{2}\right)$ of 0.941 . This result further suggests that $\mathrm{AN}-\mathrm{CS}-\mathrm{Arg} / \mathrm{Cur} \mathrm{NPs}$ exhibit a continuous and slow-release behavior for Cur.

\section{Mucoadhesion}

The percentage adhesion of CS NPs and AN-CS-Arg/Cur NPs to the colon of excised rat tissue is presented in Figure 11. As shown in Figure 11, 74.21\% $\pm 4.33 \%$ of the experimental
A

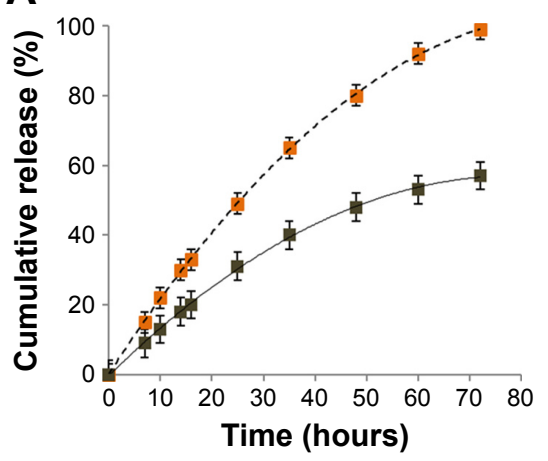

B

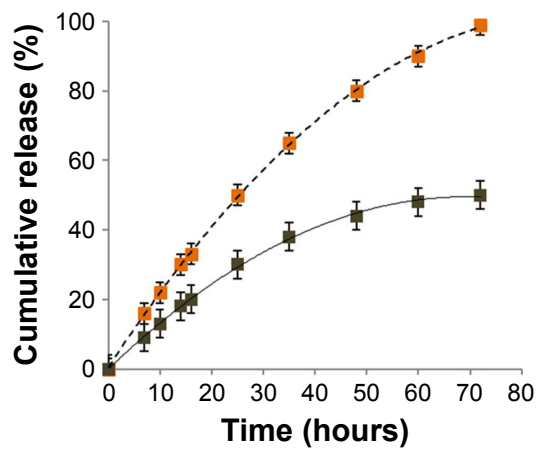

Free curcumin

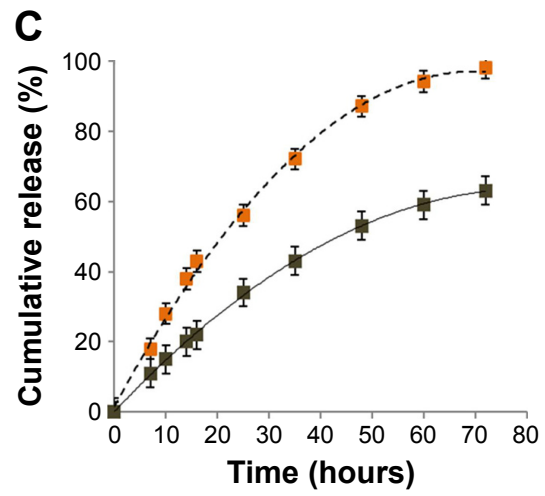

C Time (hours)

Figure 10 (A) Sustained release pattern of Cur from AN-CS-Arg/Cur NPs at pH 2.0. (B) Sustained release pattern of Cur from AN-CS-Arg/Cur NPs at pH 5.0. (C) Sustained release pattern of Cur from AN-CS-Arg/Cur NPs at pH 6.8.

Abbreviations: AN, acrylonitrile; Arg, arginine; CS, chitosan; Cur, curcumin; NPs, nanoparticles. 


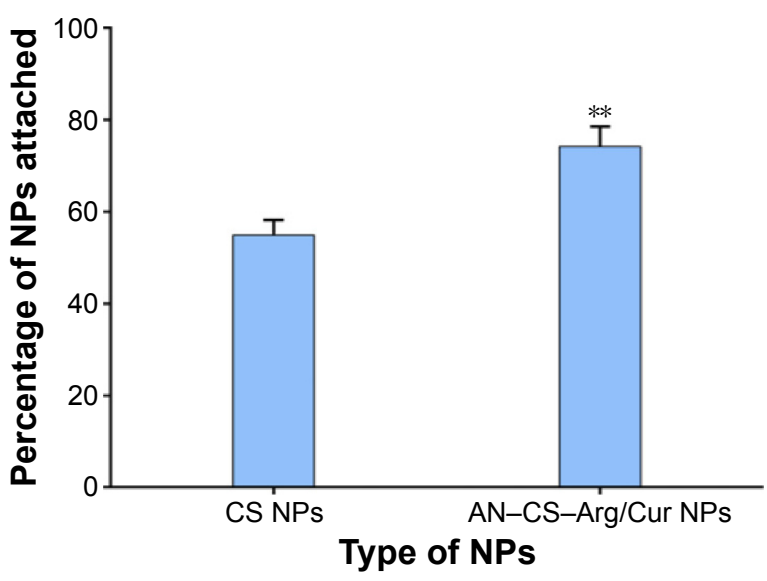

Figure II Percentage of attachment of NPs to excised colon of rat after I-hour incubation at $37^{\circ} \mathrm{C}$.

Notes: Data are expressed as mean $\pm S D(n=3)$. $* * P<0.01$ compared with CS NPs. Abbreviations: AN, acrylonitrile; Arg, arginine; CS, chitosan; Cur, curcumin; NPs, nanoparticles; SD, standard deviation.

NPs were bound to the colon, while $55.12 \% \pm 3.20 \%$ of control CS NPs were found attached with colon showing a difference of $19 \%(P<0.01)$. This result demonstrated that NPs based on amphiphilic CS derivative showed greater mucoadhesion compared with unmodified CS. This increased mucoadhesion might be due to combinational effects of CS, AN, Arg, and Cur as fabricated in the synthesized NPs. CS has been well reported to have mucoadhesive nature $;{ }^{36,37,90} \mathrm{AN}$ may promote mucoadhesion by hydrophobic interactions as earlier reports demonstrate that acrylic acid-based derivatives such as poly acrylic acid and cyanoacrylate possess mucoadhesive properties. ${ }^{91-93}$ This mucoadhesive nature of two polymers was further augmented by Arg to increase the overall surface charge of NPs while Cur partly play its role via $\pi-\pi$ interaction with mucus glycoproteins. The result is being in agreement with previously published report. ${ }^{94}$

\section{In vitro cytotoxicity study}

Figure 12A shows the percentage of cell viability as a function of the concentration of the blank AN-CS-Arg NPs. Results showed that blank AN-CS-Arg NPs in all the studied concentrations have no effects on cell viability of HT-29 cells, suggesting blank AN-CS-Arg NPs might be good biocompatible carriers.

Figure 12B shows the percentage of cell viability as a function of the concentration of the Cur. In HT-29 cell lines, the $\mathrm{IC}_{50}$ (half maximal inhibitory concentration) of AN-CS-Arg/ Cur NPs and Cur solution was $15 \mu \mathrm{g} / \mathrm{mL}$ and $28.50 \mu \mathrm{g} / \mathrm{mL}$, respectively. Results showed that for both Cur solution and AN-CS-Arg/Cur NPs, the antitumor activity increased the concentration dependently. For the concentration of Cur below $2.7 \mu \mathrm{g} / \mathrm{mL}$, no significant differences in antitumor activity were observed for two formulations. However, compared with Cur solution, the cytotoxicity of AN-CS-Arg/Cur NPs increased significantly $(P<0.05)$ when the concentration of Cur was above $5 \mu \mathrm{g} / \mathrm{mL}$. The increased cytotoxic effect of the drug-loaded AN- and Arg-modified CS NPs could be attributed to the better penetration of the drug in the tumor cells due to the carrier (AN- and Arg-modified CS). Arg has been reported as a potential valuable tool for drug delivery due to its ability to improve the cellular uptake and enhance the permeation with minimal toxicity. ${ }^{95-97}$

\section{Intracellular uptake of Cur-loaded AN- and Arg-modified CS NPs}

To further confirm the relationship between the anticancer activities and cell uptake, we observed the fluorescence of HT-29 cells after incubation for 3 hours at $37^{\circ} \mathrm{C}$ with free Cur and AN-CS-Arg/Cur NPs, respectively, at an equal concentration of $7.5 \mu \mathrm{g} / \mathrm{mL}$. As shown in Figure 13, it clearly
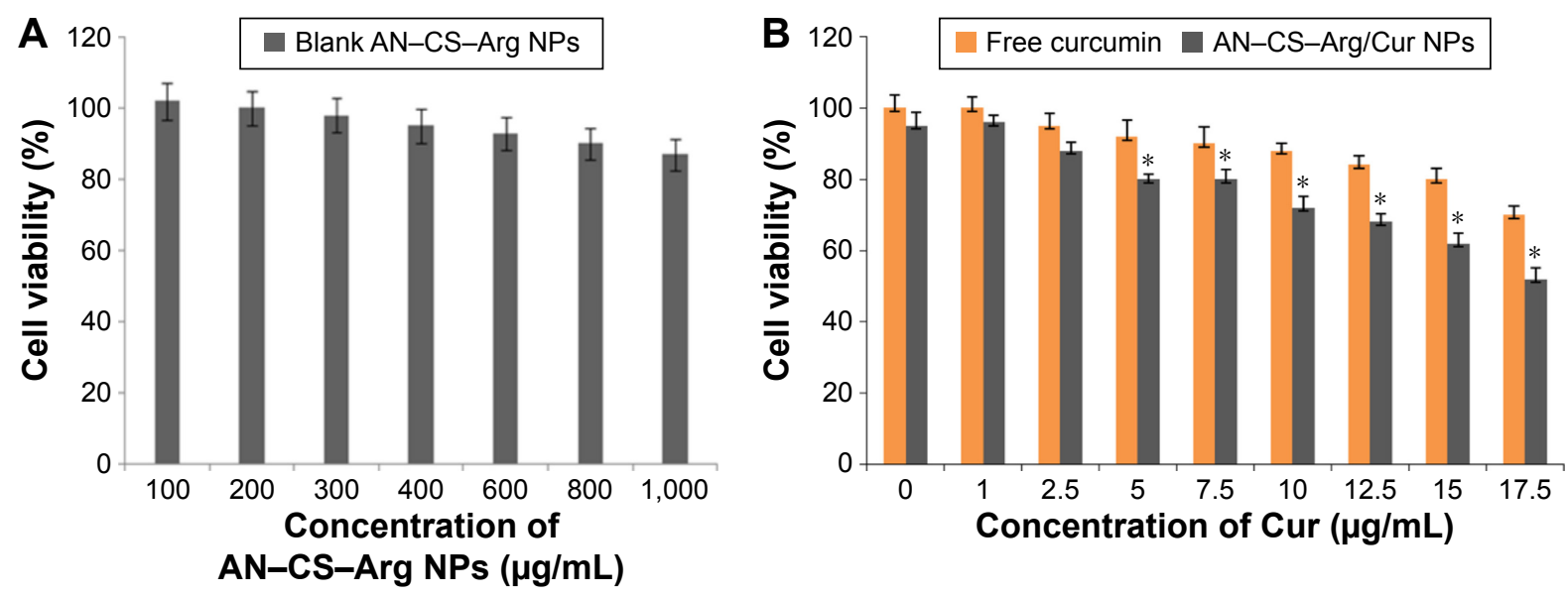

Figure 12 (A) Cytotoxicity of different concentrations of blank AN-CS-Arg NPs in HT-29 cells. (B) Cytotoxicity effect of different concentrations of AN-CS-Arg/Cur NPs in HT-29 cells. Data are expressed as mean $\pm S D(n=3)$. $* P<0.05$ compared with free Cur solution.

Abbreviations: AN, acrylonitrile; Arg, arginine; CS, chitosan; Cur, curcumin; NPs, nanoparticles; SD, standard deviation. 


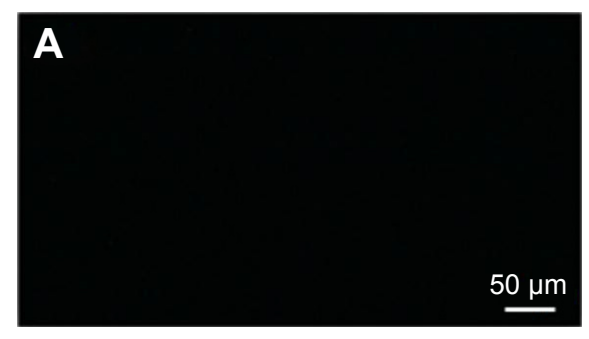

Control

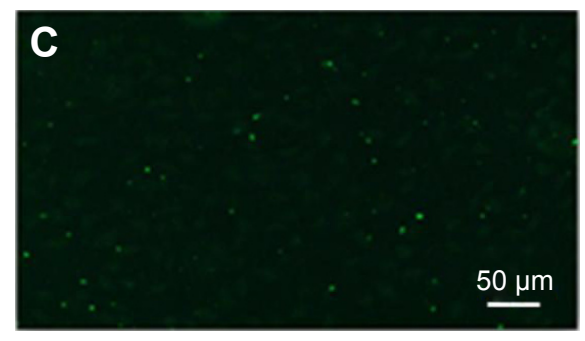

Free curcumin

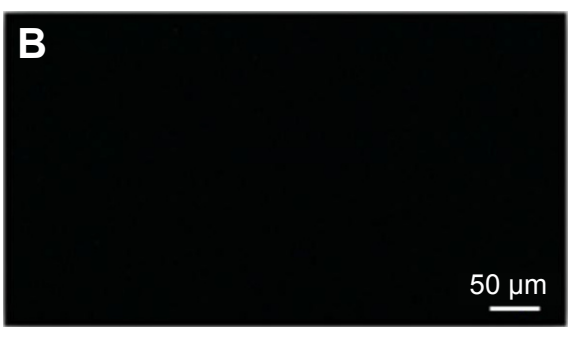

Empty AN-CS-Arg NPs

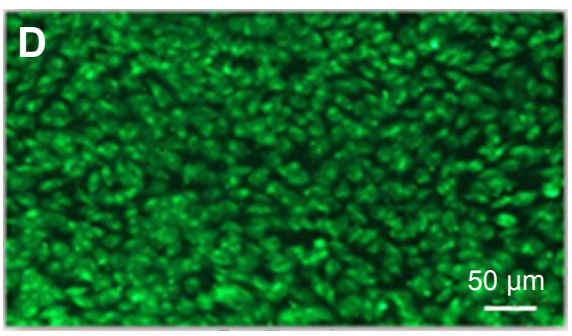

AN-CS-Arg/Cur NPs

Figure 13 Fluorescence microscopic images of the uptake of HT-29 cells of free Cur and AN-CS-Arg/Cur NPs after incubation with $7.5 \mu g / \mathrm{mL}$ at $37^{\circ} \mathrm{C}$ for 3 hours. Notes: (A) Fluorescence images of control cells (without any treatment); (B) Cells treated with blank AN-CS-Arg NPs; (C) Cells treated with free Cur solution; and (D) Cells treated with AN-CS-Arg/Cur Nps. Original magnification 100x.

Abbreviations: AN, acrylonitrile; Arg, arginine; CS, chitosan; Cur, curcumin; NPs, nanoparticles.

observed that the cells treated with AN-CS-Arg/Cur NPs showed profound fluorescence intensity compared with cells treated with native Cur. The fluorescence of cells treated with native Cur is relatively faint. However, the fluorescence of HT-29 cells is greatly enhanced, and it can be clearly seen in the of HT-29 cells after treated with AN-CS-Arg/Cur NPs. This result showed that AN-CS-Arg/Cur NPs were more effective in the enhancement of the uptake of Cur. Our results are being in agreement with other Cur nanoparticulate formulations that were more effective than free Cur against the growth of cancer cell lines due to enhanced cell uptake..$^{70,98}$

\section{Pharmacokinetics and in vivo oral bioavailability}

The main pharmacokinetic parameters of free Cur and Curloaded AN- and Arg-modified CS NPs (AN-CS-Arg/Cur NPs) following the oral administration of $100 \mathrm{mg} / \mathrm{kg}$ in rats are listed in Table 3, and the mean plasma concentrationtime curves are shown in Figure 14. As listed in Table 3, the peak plasma concentration $\left(C_{\max }\right)$ was significantly higher for NPs-treated group compared with the group treated with free
Cur $(P<0.01)$. Similarly, area under the concentration-time curve (area under the concentration-time curve $[\mathrm{AUC}]_{0-24 \text { hours }}$ ) of the NPs-administered group was greater than the control group $(P<0.01)$. Overall, these results show that currently synthesized NPs have higher plasma concentration, lower clearance, and longer half-life compared with free Cur. The relative bioavailability of NPs as calculated by the following equation: $F_{\text {rel }}(\%)=\left(100 \times \mathrm{AUC}_{\mathrm{A}} \operatorname{dose}_{\mathrm{B}} / \mathrm{AUC}_{\mathrm{B}}\right.$ dose $\left._{\mathrm{A}}\right)$ was $454 \%$, indicating that the absorption of Cur increased when it was encapsulated in a nanoformulation. Similar results were also found in other Cur nanoformulations. ${ }^{99,100}$ This remarkable increase in absorption might be due to higher affinity between NPs and mucous membrane. In GIT, the membranes on epithelial cells are lipidic in nature causing better dispersibility of Cur, thereby prolonging residence time of drug in GIT. The mucoadhesive nature of CS resulted from interaction between positively charged CS and negatively charged mucin contributes to further prolong the contact time between CS and absorptive surface. This property of CS was further augmented in our NPs due to fabrication with Arg, which not only contribute to increase the surface charge of NPs

Table 3 Pharmacokinetic parameters of Cur and AN-CS-Arg/Cur NPs in mice plasma after oral administration

\begin{tabular}{|c|c|c|c|c|c|c|c|c|}
\hline Formulations & $\begin{array}{l}\text { Dose } \\
(\mathrm{mg} / \mathrm{kg})\end{array}$ & $\begin{array}{l}\text { AUC }_{0-24 \text { hours }} \\
\text { (mg/L hour) }\end{array}$ & $\begin{array}{l}\text { MRT }_{0-24} \\
\text { (hours) }\end{array}$ & $\begin{array}{l}\text { CL/F (I/h } \\
\text { per } \mathrm{kg})\end{array}$ & $\begin{array}{l}t_{1 / 2} \\
\text { (hours) }\end{array}$ & $\begin{array}{l}T_{\max } \\
\text { (hours) }\end{array}$ & $C_{\max }(\mathrm{mg} / \mathrm{L})$ & $\begin{array}{l}F_{\text {rel }} \\
(\%)\end{array}$ \\
\hline Cur solution & 100 & $65.12 \pm 7.42$ & $4.33 \pm 0.67$ & $0.34 \pm 0.29$ & $0.90 \pm 0.89$ & 1.00 & $11.00 \pm 1.17$ & - \\
\hline AN-CS-Arg/Cur NPs & 100 & $295.47 \pm 82.44^{* *}$ & $3.40 \pm 0.75$ & $0.72 \pm 0.80 *$ & $1.15 \pm 0.30 *$ & 2.00 & $99.72 \pm 30.47^{* *}$ & 453.73 \\
\hline
\end{tabular}

Notes: $* P<0.05 ; * * P<0.01$ vs Cur solution. Data are expressed as mean $\pm S D$.

Abbreviations: Arg, arginine; AN, acrylonitrile; AUC, area under the curve; CS, chitosan; Cur, curcumin; NPs, nanoparticles; MRT, mean residence time; CL/F, apparent total clearance of the drug from plasma after oral administration. 


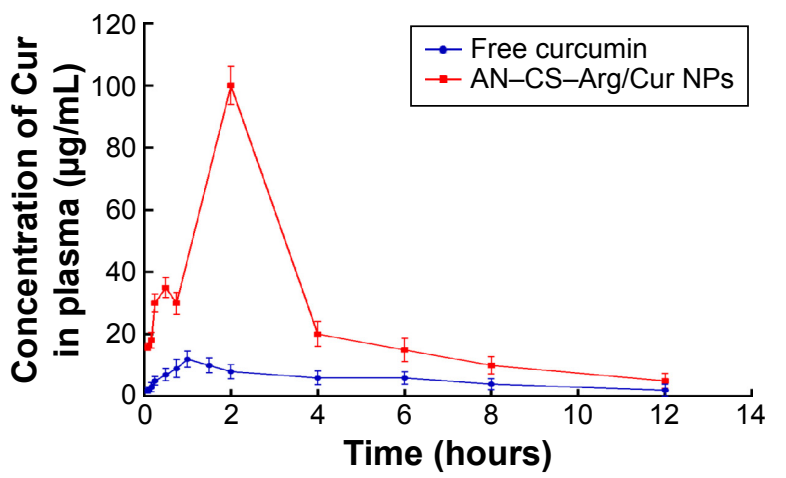

Figure I 4 Plasma concentration-time profile of Cur in rats following the single oral administration with free Cur and AN-CS-Arg/Cur NPs at a dose of $100 \mathrm{mg} / \mathrm{kg}$. Note: Data are expressed as mean $\pm S D(n=6)$.

Abbreviations: AN, acrylonitrile; Arg, arginine; CS, chitosan; Cur, curcumin; NPs, nanoparticles; SD, standard deviation.

but also enhance the permeation across the cell membrane. Thus, promoting absorption results in higher bioavailability. In addition, the carrier could shield Cur against metabolic degradation in GIT and in blood circulation before Cur is released from NPs, which could be a second reason attributed to the improvement of bioavailability. ${ }^{101,102}$ However, this is worth noticing that the bioavailability was still not high enough with regard to the administered dose that might be due to the production of metabolites during the process of absorption, metabolism, and biotransformation..$^{85}$

\section{Conclusion}

Our results demonstrated that AN- and Arg-modified CS conjugate (AN-CS-Arg) was successfully synthesized. Self-assembled NPs based on AN-CS-Arg conjugate were developed by sonication method. The aqueous solubility of Cur was significantly enhanced after encapsulation into ANand Arg-modified CS NPs. The Cur-loaded AN- and Argmodified CS NPs (AN-CS-Arg/Cur) showed the advantages of narrow size distribution, high drug encapsulation and LE, sustained release, and more importantly improved mucoadhesion. Furthermore, they exhibited enhanced cell uptake, superior growth inhibition against tumor cells, and improved oral bioavailability over native Cur. These preliminary studies indicated the potential of the currently prepared NPs in its possible applications to improve the solubility and anticancer activity of Cur. However, further studies in experimentally induced colitis animal models are needed to evaluate the efficacy of these NPs in the treatment of colorectal cancers and inflammatory bowel disease.

\section{Acknowledgment}

This study was supported by High-Tech Research and Development Plan (863) of China (2012AA091605).

\section{Disclosure}

The authors report no conflicts of interest in this work.

\section{References}

1. World Health Organization [webpage on the Internet]. Cancer. Available from: http://www.who.int/mediacentre/factsheets/fs297/en/. Accessed February 4, 2016.

2. Akhter S, Ahmad I, Ahmad MZ, et al. Nanomedicines as cancer therapeutics: current status. Curr Cancer Drug Targets. 2013;13(4):362-378.

3. Acharya S, Sahoo SK. PLGA nanoparticles containing various anticancer agents and tumour delivery by EPR effect. Adv Drug Deliv Rev. 2011;63(3):170-183.

4. Hwang HY, Kim IS, Kwon IC, Kim YH. Tumor targetability and antitumor effect of docetaxel-loaded hydrophobically modified glycol chitosan nanoparticles. J Control Release. 2008;128(1):23-31.

5. Akhter S, Ahmad Z, Singh A, et al. Cancer targeted metallic nanoparticle: targeting overview, recent advancement and toxicity concern. Curr Pharm Des. 2011;17(18):1834-1850.

6. International Agency for Research on Cancer [webpage on the Internet]. World Cancer Report 2014. Available from: http://www.iarc.fr/en/ publications/books/wcr/wcr-order.php. Accessed February 4, 2016.

7. Feng SS, Mei L, Anitha P, et al. Poly(lactide)-vitamin E derivative/ montmorillonite nanoparticle formulations for the oral delivery of Docetaxel. Biomaterials. 2009;30:3297-3306.

8. Benival DM, Devarajan PV. Lipomer of doxorubicin hydrochloride for enhanced oral bioavailability. Int J Pharm. 2012;423(2):554-561.

9. Mazzaferro S, Bouchemal K, Ponchel G. Oral delivery of anticancer drugs III: formulation using drug delivery systems. Drug Discov Today. 2013;18(1-2):99-104.

10. Thanki K, Gangwal RP, Sangamwar AT, Jain S. Oral delivery of anticancer drugs: challenges and opportunities. J Control Release. 2013; 170(1):15-40.

11. Mazzaferro S, Bouchemal K, Ponchel G. Oral delivery of anticancer drugs I: general considerations. Drug Discov Today. 2013;18(1-2):25-34.

12. Maheshwari RK, Singh AK, Gaddipati J, Srimal RC. Multiple biological activities of curcumin: a short review. Life Sci. 2006;78(18): 2081-2087.

13. Sharma RA, Gescher AJ, Steward WP. Curcumin: the story so far. Eur J Cancer. 2005;41(13):1955-1968.

14. Lopresti AL, Hood SD, Drummond PD. Multiple antidepressant potential modes of action of curcumin: a review of its anti-inflammatory, monoaminergic, antioxidant, immune-modulating and neuroprotective effects. J Psychopharmacol. 2012;26(12):1512-1524.

15. Fan X, Zhang C, Liu DB, Yan J, Liang HP. The clinical applications of curcumin: current state and the future. Curr Pharm Des. 2013;19(11): 2011-2031.

16. Lin JK, Lin-Shiau SY. Mechanisms of cancer chemoprevention by curcumin. Proc Natl Sci Counc Repub China B. 2001;25(2):59-66.

17. Garcea G, Jones DJ, Singh R, et al. Detection of curcumin and its metabolites in hepatic tissue and portal blood of patients following oral administration. Br J Cancer. 2004;90(5):1011-1015.

18. Shelma R, Sharma CP. In vitro and in vivo evaluation of curcumin loaded lauroyl sulphated chitosan for enhancing oral bioavailability. Carbohydr Polym. 2013;95(1):441-448.

19. Dhule SS, Penfornis P, He J, et al. The combined effect of encapsulating curcumin and C6 ceramide in liposomal nanoparticles against osteosarcoma. Mol Pharm. 2014;11(2):417-427.

20. Harada T, Giorgio L, Harris TJ, et al. Diamide linked $\gamma$-cyclodextrin dimers as molecular-scale delivery systems for the medicinal pigment curcumin to prostate cancer cells. Mol Pharm. 2013;10(12): 4481-4490.

21. Muller RH, Keck CM. Challenges and solutions for the delivery of biotech drugs - a review of drug nanocrystal technology and lipid nanoparticles. $J$ Biotech. 2004;113:151-155.

22. Tiyaboonchai $\mathrm{W}$, Tungpradit $\mathrm{W}$, Plianbangchang P. Formulation and characterization of curcuminoids loaded solid lipid nanoparticles. Int $J$ Pharm. 2007;337(1-2):299-306. 
23. Bisht S, Feldmann G, Soni S, et al. Polymeric nanoparticle-encapsulated curcumin ("nanocurcumin"): a novel strategy for human cancer therapy. J Nanobiotech. 2007;5:3-21.

24. Kumar V, Lewis SA, Mutalik S, et al. Biodegradable microspheres of curcumin for the treatment of inflammation. Indian J Phys Pharmacol. 2002;46:209-217.

25. Sou K, Inenaga S, Takeoka S, Tsuchida E. Loading of curcumin into macrophages using lipid-based nanoparticles. Int J Pharm. 2008; 352(1-2):287-293.

26. Dhule SS, Penfornis P, Frazier T, et al. Curcumin-loaded $\gamma$-cyclodextrin liposomal nanoparticles as delivery vehicles for osteosarcoma. Nanomedicine. 2012;8(4):440-451.

27. Vemula PK, Li J, John G. Enzyme catalysis: tool to make and break amygdalin hydrogelators from renewable resources: a delivery mode for hydrophobic drugs. J Am Chem Soc. 2006;128(27):8932-8938.

28. Li L, Ahmed B, Mehta K, Kurzrock R. Liposomal curcumin with and without oxaliplatin: effects on cell growth, apoptosis, and angiogenesis in colorectal cancer. Mol Cancer Ther. 2007;6(4):1276-1282.

29. Wang D, Veena MS, Stevenson K, et al. Liposome encapsulated curcumin suppresses growth of head and neck squamous cell carcinoma in vitro and in xenografts through the inhibition of nuclear factor $\mathrm{\kappa B}$ by an AKT independent pathway. Clin Cancer Res. 2008;14:6228-6236.

30. Zheng H, Zhang XQ, Xiong FL, et al. Preparation, characterization, and tissue distribution in mice of lactosaminated carboxymethyl chitosan nanoparticles. Carbohydr Polym. 2011;83:1139-1145.

31. Soppimath KS, Aminabhavi TM, Kulkarni AR, Rudzinski WE. Biodegradable polymeric nanoparticles as drug delivery devices. J Control Release. 2001;70(1-2):1-20.

32. Ahmad MZ, Alkahtani SA, Akhtar S, et al. Progress in nanotechnologybased drug carrier in designing of curcumin nanomedicines for cancer therapy: current state-of-the-art. J Drug Target. 2016;24(4):273-293.

33. Roldo M, Hornof M, Caliceti P, Bernkop-Schnürch A. Mucoadhesive thiolated chitosans as platforms for oral controlled drug delivery: synthesis and in vitro evaluation. Eur J Pharm Biopharm. 2004;57(1):115-121.

34. Malafaya PB, Santos TC, Van Griensven M, Reis RL. Morphology, mechanical characterization and in vivo neo-vascularization of chitosan particle aggregated scaffolds architectures. Biomaterials. 2008; 29(29):3914-3926.

35. Muzzarelli C, Stanic V, Gobbi L, et al. Spray-drying of solutions containing chitosan together with polyuronans and characterisation of the microspheres. Carbohydr Polym. 2004;57:73-82.

36. Jayakumar R, Menon D, Manzoor K, et al. Biomedical applications of chitin and chitosan based nanomaterials-a short review. Carbohydr Polym. 2010;82:227-232.

37. Liu Y, Di Zang H, Kong M, et al. In vitro evaluation of mucoadhesion and permeation enhancement of polymeric amphiphilic nanoparticles. Carbohydr Polym. 2012;89(2):453-460.

38. Jayakumar R, Prabaharan M, Reis RL, Mano JF. Graft copolymerized chitosan - present status and applications. Carbohydr Polym. 2005;62: $142-158$

39. Jayakumar R, Nwe N, Tokura S, Tamura H. Sulfated chitin and chitosan as novel biomaterials. Int J Biol Macromol. 2007;40(3):175-181.

40. Casettari L, Vllasaliu D, Lam JK, Soliman M, Illum L. Biomedical applications of amino acid-modified chitosans: a review. Biomaterials. 2012;33(30):7565-7583.

41. Gao Y, Xu Z, Chen S, Gu W, Chen L, Li Y. Arginine-chitosan/DNA self-assemble nanoparticles for gene delivery: in vitro characteristics and transfection efficiency. Int J Pharm. 2008;359(1-2):241-246.

42. Wernersson E, Heyda J, Kubícková A, Krízek T, Coufal P, Jungwirth P. Effect of association with sulfate on the electrophoretic mobility of polyarginine and polylysine. J Phys Chem B. 2010;114(36): 11934-11941.

43. Park S, Lee SK, Lee KY. Oligoarginine-modified chitosan for siRNA delivery. J Control Release. 2011;152:165-166.

44. Zhu DW, Zhang HL, Bai JG, et al. Enhancement of transfection efficiency for HeLa cells via incorporating arginine moiety into chitosan. Chin Sci Bull. 2007;52:3207-3215.
45. Akagi T, Kaneko T, Kida T, Akashi M. Preparation and characterization of biodegradable nanoparticles based on poly (g-glutamic acid) with 1-phenylalanine as a protein carrier. J Control Release. 2005;108: 226-236.

46. Park JH, Saravanakumar G, Kim K, Kwon IC. Targeted delivery of low molecular drugs using chitosan and its derivatives. Adv Drug Deliv Rev. 2010;62(1):28-41

47. Liu Z, Jiao Y, Wang Y, Zhou C, Zhang Z. Polysaccharides-based nanoparticles as drug delivery systems. Adv Drug Deliv Rev. 2008;60(15): $1650-1662$

48. Behan N, Birkinshaw C, Clarke N. Poly n-butyl cyanoacrylate nanoparticles: a mechanistic study of polymerization and particle formation. Biomaterials. 2001;11:1335-1344.

49. Juan BSD, Briesen HV, Gelperima SE, Kreuter J. Cytotoxicity of doxorubicin bound to poly(butyl cyanoacrylate) nanoparticles in rat glioma cell lines using different assays. J Drug Target. 2006;14(9):614-622.

50. Maksimenko O, Pavlov E, Toushov E, et al. Radiation sterilization of doxorubicin bound to poly (butyl cyanoacrylate) nanoparticles. Int $J$ Pharm. 2008;356:325-332.

51. Reddy LH, Sharma RK, Murthy RSR. Enhanced tumour uptake of doxorubicin loaded poly(butyl cyanoacrylate) nanoparticles in mice bearing Dalton's lymphoma tumour. J Drug Target. 2004;12:443-451.

52. Bisht S, Mizuma M, Feldmann G, et al. Systemic administration of polymeric nanoparticle-encapsulated curcumin (NanoCurc) blocks tumor growth and metastases in preclinical models of pancreatic cancer. Mol Cancer Ther. 2010;9(8):2255-2264.

53. Huang CY, Chen CM, Lee YD. Synthesis of high loading and encapsulation efficient paclitaxel-loaded poly (n-butyl cyanoacrylate) nanoparticles via miniemulsion. Int J Pharm. 2007;338(1-2):267-275.

54. Miyazaki S, Takahashi A, Kubo W, Bachynsky J, Löebenberg R. Poly n-butylcyanoacrylate (PNBCA) nanocapsules as a carrier for NSAIDs: in vitro release and in vivo skin penetration. J Pharm Pharm Sci. 2003; $6(2): 240-245$.

55. Page-Clisson ME, Pinto-Alphandary H, Ourevitch M, Andremont A, Couvreur P. Development of ciprofloxacin-loaded nanoparticles: physicochemical study of the drug carrier. J Control Release. 1998;56(1-3): 23-32.

56. Tasset C, Barette N, Thysman S, et al. Polyisobutylcyanoacrylate nanoparticles as sustained release system for calcitonin. J Control Release. 1995;33:23-30.

57. Sun M, Gao Y, Guo CY, et al. Enhancement of transport of curcumin to brain in mice by poly (N-butylcyanoacrylate) nanoparticle. J Nanopart Res. 2010;12:3111-3122.

58. Duan J, Zhang Y, Han S, et al. Synthesis and in vitro/in vivo anti-cancer evaluation of curcumin-loaded chitosan/poly(butyl cyanoacrylate) nanoparticles. Int J Pharm. 2010;400(1-2):211-220.

59. Abou-Zeid NY, Waly AI, Kandile NG, et al. Preparation, characterization and antibacterial properties of cyanoethylchitosan/cellulose acetate polymer blended films. Carbohydr Polym. 2011;84:223-230.

60. Yin L, Su T, Chang J, et al. Arginine and acrylonitrile modified chitosan nanoparticles for anticancer drug delivery. Nano. 2014;9: 14500751-14500759.

61. Shigemasa Y, Matsuura H, Sashiwa H, Saimoto H. Evaluation of different absorbance ratios from infrared spectroscopy for analyzing the degree of deacetylation in chitin. Int J Biol Macromol. 1996;18(3):237-242.

62. Sashiwa H, Shigemasa Y. Chemical modification of chitin and chitosan 2: preparation and water soluble property of $\mathrm{N}$-acylated or $\mathrm{N}$-alkylated partially deacetylated chitins. Carbohydr Polym. 1999;39:127-138.

63. Kubota N, Tatsumoto N, Sano T, Toya K. A simple preparation of half $\mathrm{N}$-acetylated chitosan highly soluble in water and aqueous organic solvents. Carbohydr Res. 2000;324(4):268-274.

64. Liu CG, Desai KG, Chen XG, Park HJ. Linolenic acid-modified chitosan for formation of self-assembled nanoparticles. J Agric Food Chem. 2005; 53(2):437-441.

65. Liu Y, Guo R. pH-dependent structures and properties of casein micelles. Biophys Chem. 2008;136(2-3):67-73. 
66. Amiji MM. Pyrene florescence study of chitosan self-association in aqueous solution. Carbohydr Polym. 1995;26:211-213.

67. Lee H, Lee K, Park TG. Hyaluronic acid-paclitaxel conjugate micelles synthesis, characterization and antitumor activity. Bioconjug Chem. 2008; 19(6):1319-1325.

68. Jithan AV, Madhavi K, Madhavi M, Prabhakar K. Preparation and characterization of albumin nanoparticles encapsulating curcumin intended for the treatment of breast cancer. Int J Pharm Investig. 2011; 1(2):119-125.

69. Santos CA, Jacob JS, Hertzog BA, et al. Correlation of two bioadhesion assays: the everted sac technique and the CAHN microbalance. J Control Release. 1999;61(1-2):113-122.

70. Mohanty C, Sahoo SK. The in vitro stability and in vivo pharmacokinetics of curcumin prepared as an aqueous nanoparticulate formulation. Biomaterials. 2010;31(25):6597-6611.

71. Anitha A, Maya S, Deepa N, et al. Efficient water-soluble biodegradable polymeric nanocarrier for the delivery of curcumin to cancer cells. Carbohydr Polym. 2011;83:452-461.

72. Liu Y, Kong M, Feng C, et al. Biocompatibility, cellular uptake and biodistribution of the polymeric amphiphilic nanoparticles as oral drug carriers. Colloids Surf B Biointerfaces. 2013;103:345-353.

73. Tao S, Peixin X, Qing L, et al. Graft copolymerization of methacrylic acid onto carboxymethyl chitosan. Eur Polym J. 2003;39:189-192.

74. Arias JL, Gallardo V, Gómez-Lopera SA, Plaza RC, Delgado AV. Synthesis and characterization of poly (ethyl-2-cyanoacrylate) nanoparticles with a magnetic core. J Control Release. 2001;77(3):309-321.

75. Maeda H, Wu J, Sawa T, Matsumura Y, Hori K. Tumor vascular permeability and the EPR effect in macromolecular therapeutics: a review. J Control Release. 2000;65(1-2):271-284.

76. Monsky WL, Fukumura D, Gohongi T, et al. Augmentation of transvascular transport of macromolecules and nanoparticles in tumors using vascular endothelial growth factor. Cancer Res. 1999;59(16):4129-4135.

77. He C, Hu Y, Yin L, Tang C, Yin C. Effects of particle size and surface charge on cellular uptake and biodistribution of polymeric nanoparticles. Biomaterials. 2010;31(13):3657-3666.

78. Shaikh J, Ankola DD, Beniwal V, Singh D, Kumar MN. Nanoparticle encapsulation improves oral bioavailability of curcumin by at least 9-fold when compared to curcumin administered with piperine as absorption enhancer. Eur J Pharm Sci. 2009;37(3-4):223-230.

79. Li Q, Liu CG, Huang ZH, Xue FF. Preparation and characterization of nanoparticles based on hydrophobic alginate derivative as carriers for sustained release of vitamin D3. J Agric Food Chem. 2011;59(5):1962-1967.

80. Raja MA, Liu C, Huang Z. Nanoparticles based on oleate alginate ester as curcumin delivery system. Curr Drug Deliv. 2015;12(5):613-627.

81. Liu J, Lihua L, Chuantong L, et al. Preparation and characterization of curcumin nanoparticles for improvement of cellular uptake. Carbohydr Polym. 2012;90:16-22.

82. Anand P, Kunnumakkara AB, Newman RA, Aggarwal BB. Bioavailability of curcumin: problems and promises. Mol Pharmacol. 2007;4(6): 807-818.

83. Yu HL, Huang QR. Enhanced in vitro anti-cancer activity of curcumin encapsulated in hydrophobically modified starch. Food Chem. 2010;119: 669-674.

84. Letchford K, Liggins R, Burt H. Solubilization of hydrophobic drugs by methoxy poly (ethylene glycol)-block-polycaprolactone diblock copolymer micelles: theoretical and experimental data and correlations. J Pharm Sci. 2008;97(3):1179-1190.
85. Sharma RA, Steward WP, Gescher AJ. Pharmacokinetics and pharmacodynamics of curcumin. Adv Exp Med Biol. 2007;595:453-470.

86. Zhang L, Qi Z, Huang Q, et al. Imprinted-like biopolymeric micelles as efficient nanovehicles for curcumin delivery. Colloids Surf B Biointerfaces. 2014;123:15-22.

87. Liu L, Li C, Li X, et al. Biodegradable polylactide/poly(ethylene glycol)/polylactide triblock copolymer micelles as anticancer drug carriers. J Appl Polym Sci. 2001;80:1976-1982.

88. Ruan G, Feng SS. Preparation and characterization of poly(lactic acid)-poly(ethylene glycol)-poly(lactic acid) (PLA-PEG-PLA) microspheres for controlled release of paclitaxel. Biomaterials. 2003; 24(27):5037-5044.

89. Muller RH, Mader K, Gohla S. Solid lipid nanoparticles (SLN) for controlled drug delivery- a review of the state of the art. Eur J Pharm Biopharm. 2000;50(1):161-177.

90. Janes KA, Calvo P, Alonso MJ. Polysaccharide colloidal particles as delivery systems for macromolecules. Adv Drug Deliv Rev. 2001; 47(1):83-97.

91. Ensign LM, Cone R, Hanes J. Oral drug delivery with polymeric nanoparticles: the gastrointestinal mucus barriers. Adv Drug Deliv Rev. 2012;64(6):557-570.

92. Lai SK, Wang YY, Hanes J. Mucus-penetrating nanoparticles for drug and gene delivery to mucosal tissues. Adv Drug Deliv Rev. 2009; 61(2):158-171.

93. Bravo-Osuna I, Vauthier C, Farabollini A, Palmieri GF, Ponchel G. Mucoadhesion mechanism of chitosan and thiolated chitosanpoly(isobutyl cyanoacrylate) core-shell nanoparticles. Biomaterials. 2007;28(13):2233-2243.

94. Chuah LH, Billa N, Roberts CJ, Burley JC, Manickam S. Curcumincontaining chitosan nanoparticles as a potential mucoadhesive delivery system to the colon. Pharm Dev Technol. 2011;18(3):591-599.

95. Fonseca SB, Pereira MP, Kelley SO. Recent advances in the use of cell-penetrating peptides for medical and biological applications. Adv Drug Deliv Rev. 2009;61(11):953-964.

96. Fischer R, Fotin-Mieczek M, Hufnagel H, Brock R. Break on through to the other side-biophysics and cell biology shed light on cellpenetrating peptides. Chembiochem. 2005;6(12):2126-2142.

97. Nagahara H, Vocero-Akbani AM, Snyder EL, et al. Transduction of full-length TAT fusion proteins into mammalian cells: TAT-p27Kip1 induces cell migration. Nat Med. 1998;4:1449-1452.

98. Gong CY, Deng SY, Wu QJ, et al. Improving antiangiogenesis and anti-tumor activity of curcumin by biodegradable polymeric micelles. Biomaterials. 2013;34(4):1413-1432.

99. Xie X, Tao Q, Zou Y, et al. PLGA nanoparticles improve the oral bioavailability of curcumin in rats: characterizations and mechanisms. J Agric Food Chem. 2011;59(17):9280-9289.

100. Gao Y, Wang C, Sun M, et al. In vivo evaluation of curcumin loaded nanosuspensions by oral administration. J Biomed Nanotechnol. 2012; 8(4):659-668.

101. Tsai YM, Jan WC, Chien CF, Lee WC, Lin LC, Tsai TH. Optimised nano-formulation on the bioavailability of hydrophobic polyphenol curcumin in freely-moving rats. Food Chem. 2011;127(3):918-925.

102. Yu H, Huang Q. Improving the oral bioavailability of curcumin using novel organogel-based nanoemulsions. J Agric Food Chem. 2012; 60(21):5373-5379.
International Journal of Nanomedicine

\section{Publish your work in this journal}

The International Journal of Nanomedicine is an international, peerreviewed journal focusing on the application of nanotechnology in diagnostics, therapeutics, and drug delivery systems throughout the biomedical field. This journal is indexed on PubMed Central, MedLine, CAS, SciSearch ${ }^{\circledR}$, Current Contents ${ }^{\circledR} /$ Clinical Medicine,

\section{Dovepress}

Journal Citation Reports/Science Edition, EMBase, Scopus and the Elsevier Bibliographic databases. The manuscript management system is completely online and includes a very quick and fair peer-review system, which is all easy to use. Visit http://www.dovepress.com/ testimonials.php to read real quotes from published authors. 